\title{
Thermal-hydraulic design methodology and trade-off studies for a dual-salt breed-and-burn molten salt reactor
}

\author{
Alisha Kasam ${ }^{\mathrm{a}, *}$, Jeong Ik Lee ${ }^{\mathrm{b}}$, Eugene Shwageraus ${ }^{\mathrm{a}}$ \\ ${ }^{a}$ Department of Engineering, University of Cambridge \\ ${ }^{b}$ Department of Nuclear and Quantum Engineering, Korea Advanced Institute of Science and Technology
}

\begin{abstract}
A methodology is developed for thermal-hydraulic analysis and design of a breed-and-burn molten salt reactor (BBMSR). By using separate fuel and coolant molten salts, the BBMSR is proposed to overcome key materials limitations of traditional breed-and-burn and molten salt reactor designs. The BBMSR fuel concept includes an inner wall that divides the ascending and descending flows of naturally convecting fuel salt. A finite-difference model (FDM) is developed to iteratively solve for the temperature and velocity distributions in both sections of the concentric fuel. The FDM is used to perform parametric studies of the effect of fuel geometry and heat generation rate on the heat transfer performance of the fuel. The FDM is then integrated into a design search algorithm that identifies the operational limits for a given BBMSR fuel geometry, within a set of defined constraints. A range of thermal-hydraulic fuel design options are evaluated, and trade-off studies are performed to identify the most promising fuel design space for competitive power production and neutronic efficiency in the BBMSR.
\end{abstract}

Keywords: Molten salt, Natural convection, Breed-and-burn

\section{Introduction}

The Breed-and-burn $(\mathrm{B} \& \mathrm{~B})$ concept is a fast reactor variant that uses natural or depleted uranium feed fuel in a once-through fuel cycle with in-situ breeding and burning (Feinberg, 1958). In a $\mathrm{B} \& \mathrm{~B}$ reactor, fertile fuel absorbs excess neutrons from the driver regions, breeding fissile material which then sustains the chain reaction by supplying excess neutrons to regions of fresh fertile

\footnotetext{
${ }^{*}$ Corresponding author
} 
feed fuel. B\&B spent fuel is disposed of directly as waste, so after initial start-up, no reprocessing or enrichment is needed for the entire operating life of the reactor. Fuel cycle costs, environmental impact, and proliferation potential are predicted to be low due to the reduction of processing stages (Petroski, 2011). The minimum fuel burnup required to sustain B\&B operation is typically on the order of 20-30\% FIMA (fissions per initial heavy-metal atom), which is similar to uranium utilisation in the fast reactor closed cycle.

This work focuses on thermal-hydraulic performance of a breed-and-burn molten salt reactor (BBMSR), which is proposed to integrate the fuel cycle advantages of B\&B operation with the operational advantages of molten salt reactors (MSRs). MSRs allow high temperature operation at atmospheric pressure, flexible fuel cycle operation, and inherent safety due to strongly negative reactivity feedback. However, long-term corrosion resistance of structural materials exposed to fuel salt remains to be demonstrated. B\&B technology is also limited by the lack of fuel and cladding materials that can survive the high required minimum burnup and fast neutron fluence in a once-through cycle.

The BBMSR offers a potential solution to the materials challenges of traditional MSRs and $\mathrm{B} \& \mathrm{~B}$ reactors. Its dual-salt configuration is based on the design of the waste-burning Stable Salt Reactor (SSR) by Moltex Energy, in which a naturally convecting fuel salt is contained in individual fuel tubes, cooled by an external salt (Scott et al., 2015). It can be shown analytically that internal natural convection of a heat-generating fluid produces a hot ascending core and a cool descending annulus separated by a velocity inflection point (Martin, 1967). Fig. 1 illustrates the reactor configuration; each fuel assembly is a bundle of individual fuel tube elements, with the fuel and coolant flow patterns shown in the expanded view. Natural convection of the fuel aids heat transfer to the coolant, and the cladding tubes may be easily replaced to achieve high fuel burnup.

A preliminary neutronic feasibility study indicated that $B \& B$ operation with natural uranium feed may be achievable in the dual-salt configuration with a large fuel volume fraction, but the assembly geometry is limited by the system's thermal-hydraulic characteristics (Kasam and Shwageraus, 2017). Because molten salts have low thermal conductivities relative to solid nuclear fuels, the BBMSR fuel tubes would be limited to very small diameters if the fuel salt were stagnant. Natural circulation within the fuel tubes may sufficiently enhance heat transfer to the coolant 

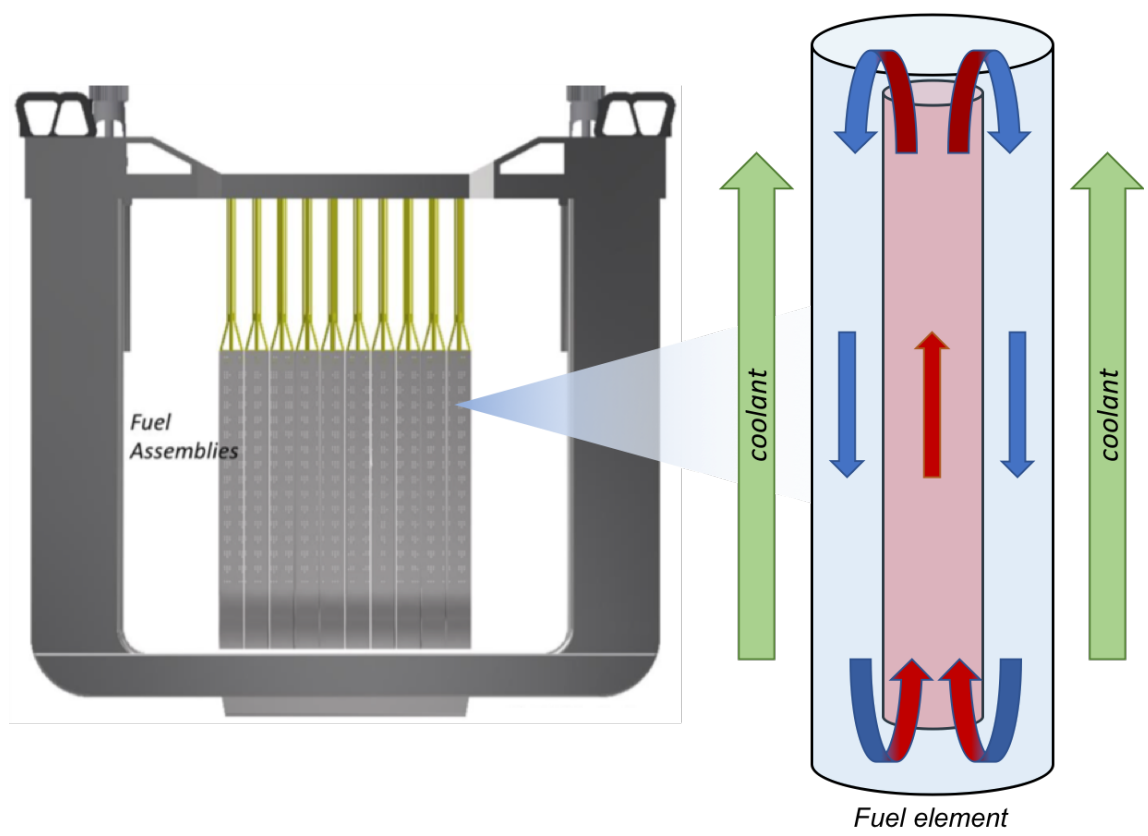

Figure 1: Moltex fuel concept

to allow the high fuel volume fraction required for $\mathrm{B} \& \mathrm{~B}$ operation and economically competitive power density. However, the physical phenomena involved in a buoyant, heat-generating fluid are unusual and complex, and existing heat transfer correlations have limited applicability in this domain.

This paper presents a method developed for thermal-hydraulic analysis and design studies of the BBMSR fuel. Section 2 introduces the characteristics of the convecting fuel and summarises a previous, complementary study exploring fundamental heat transfer behaviour in convection of a fluid with internal heat generation (IHG) (Kasam et al., 2019). Section 3 describes a finitedifference model (FDM) developed to calculate velocity and temperature distributions in the convecting fuel; the model is then used to investigate thermal-hydraulic behaviour of the BBMSR fuel by comparing various configurations. Section 4 describes a fuel design search algorithm based on the FDM, developed for efficient exploration of the design space within defined operational constraints. In Section 5, the design algorithm is used to assess the thermal-hydraulic trade-offs and performance limitations of the BBMSR fuel concept. 


\section{Fuel convection analysis}

A simplified analytical representation of the convecting fuel system predicts a continuous flow pattern over the length of the tube, where the internal fluid boundary has a fixed position at the velocity inflection point (Martin, 1967). This fuel concept is modified to include a physical wall dividing the hot ascending and cool descending flows into concentric sections, to aid in the formation of a single convection loop as shown in Fig. 1. This prevents smaller convection cells from developing in the high aspect ratio fuel elements, a condition that can localize heat transfer and deteriorate the fuel performance. Although buoyancy remains the only flow driver in the modified concentric tube configuration, the flow is classified as forced convection because the global temperature difference between core and annulus sections induces an external pressure gradient at the inlet and outlet of each section. With sufficiently strong heat generation conditions, the radial temperature differences within each fuel section can also induce local buoyancy effects that distort the velocity profile and produce a mixed convection condition.

In this study, the inner fuel channel is designated as section A, and the outer annulus as section B. Since the location of the boundary between flow sections is fixed and predetermined in the concentric fuel concept, a numerical finite-difference approach can be used to model the axial and radial exchange of energy in the fuel tube. The mass flow rate and axial bulk temperature profile in each fuel section can therefore be determined using correlations for pressure drop and heat transfer. First, existing convective heat transfer correlations are qualitatively evaluated to assess their suitability for the concentric fuel concept.

\subsection{Evaluation of convection correlations}

In internal mixed convection, the heat transfer coefficient may be increased or decreased by up to one order of magnitude compared to forced convection (Aicher and Martin, 1997). The effect on heat transfer depends on whether buoyancy is aiding or opposing the direction of forced convection, and whether the flow is laminar or turbulent. In the laminar flow regime, aiding mixed convection enhances heat transfer compared to pure forced or pure natural convection, while opposing mixed convection impairs heat transfer. The converse is true for turbulent aiding and opposing mixed convection. The transition to turbulence in mixed convection is difficult to 
predict, and occurs at lower critical values of Grashof and Reynolds numbers than for either of the pure convection conditions (Jackson et al., 1989).

While numerous heat transfer correlations have been successfully developed for mixed convection with external wall heating, new, tailored models are needed for convection with IHG like in the BBMSR concentric fuel. Prior studies report the complex and unique heat transfer characteristics of forced and natural convection in fluids with IHG. Simulated and observed phenomena include unstable thermal stratification, turbulence at low Rayleigh number, and oscillating temperature and velocity fields (Sehgal et al., 1996; Zhang et al., 2018; Pini et al., 2016). A numerical and experimental study of a natural circulation loop with IHG predicts nearly uniform radial temperature profiles and higher buoyant velocities than with wall heating alone (Jeong et al., 2018). These findings indicate that the characteristics of a flow with distributed heat source depart significantly from heat transfer theory and correlations developed for externally heated flows.

Established mixed convection theory can, however, be used to inform the selection of correlations for estimating heat transfer in the concentric BBMSR fuel. Four heat transfer regimes are qualitatively compared: laminar and turbulent forced convection, and laminar and turbulent mixed convection with IHG. Turbulence increases the heat transfer coefficient compared to laminar flow, while mixed convection may increase or decrease heat transfer as described above (Jackson et al., 1989). Prior studies indicate that IHG improves the heat transfer coefficient compared to external heating; since the extent of improvement is thus far unknown, mixed convection with IHG can be conservatively treated like mixed convection with external heating, for the purposes of regime comparison. The four regimes are arranged in order of increasing heat transfer coefficient as shown in Figs. 2 and 3 for the ascending and descending flows, respectively.

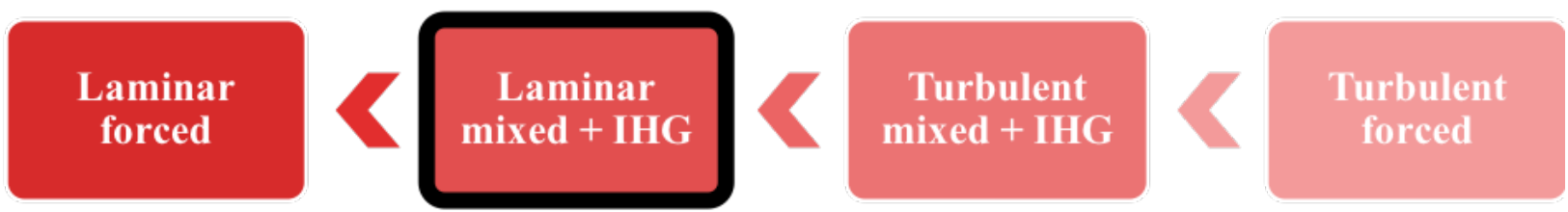

Figure 2: Heat transfer correlation selection for fuel section A, ascending core

The ascending flow in section A may be either laminar or turbulent, depending on the fuel's 


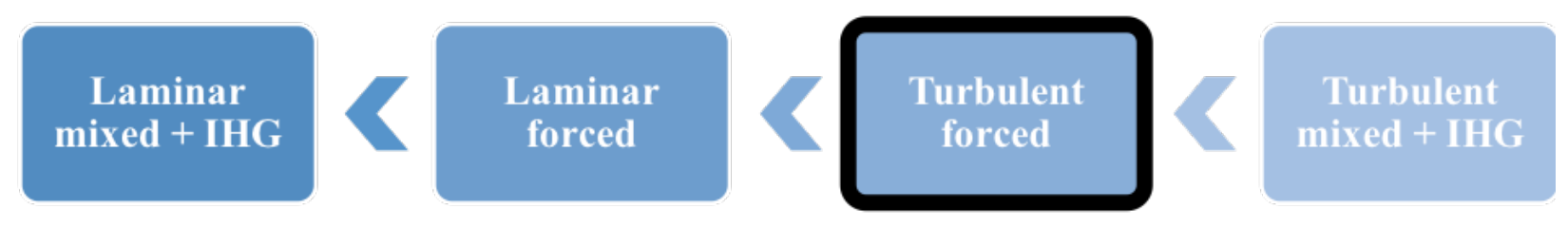

Figure 3: Heat transfer correlation selection for fuel section B, descending annulus

fluid properties and geometry. If the flow is turbulent, buoyancy can cause localized laminarization, which deteriorates heat transfer (Jackson et al., 1989). Therefore, given the uncertainty in transition to turbulence in mixed convection, a laminar correlation is preferred to produce a more conservative fuel design. There are no existing correlations for laminar mixed convection with IHG, but the laminar forced convection coefficient $(N u=4.36)$ may be overly conservative and constrain the fuel design excessively. A separate study is therefore performed to obtain a new heat transfer correlation for ascending pipe flow including the effects of buoyancy and IHG, based on numerical simulations in CFD as described in the next section.

In the descending flow of the annular channel, buoyancy opposes the direction of motion. When such flow is laminar, buoyancy resists the fluid motion and impairs heat transfer. However, Jackson et al. (1989) note that "virtually no laminar flow heat transfer measurements have been reported for conditions where free convection opposes forced convection (heated downward flow . . . )." Opposing buoyancy induces instabilities, leading to the onset turbulence at low Reynolds number. It is therefore safe to assume that section B is turbulent for all practical fuel configurations, but the strong instability makes it very challenging to simulate turbulent convection with buoyancy and IHG in CFD. Since buoyancy enhances heat transfer in turbulent flow, Figure 3 shows that section B can be conservatively approximated as forced rather than mixed convection, using the Dittus-Boelter correlation:

$$
N u_{B}=0.023 \operatorname{Re}_{B}^{0.8} \operatorname{Pr}^{0.4}
$$

\subsection{Mixed convection CFD study}

The open-source CFD package OpenFOAM was used to simulate laminar ascending mixed convection with IHG, in a system representative of section A of the concentric fuel concept (The 
OpenFOAM Foundation, 2017). Rather than simulating every fuel configuration of interest, a heat transfer correlation was developed based on a small number of simulations covering a range of geometries and boundary configurations of interest. The correlation facilitates efficient exploration of BBMSR design options, such as fuel tube geometry and power rating, that are bound by the maximum fuel temperature.

The thermophysical properties of the Moltex SSR fuel salt $\mathrm{NaCl}-\mathrm{UCl}_{3}-\mathrm{PuCl}_{3}(60-20-20 \mathrm{~mol} \%)$ were used for the CFD modelling since the lower viscosity of the preferred BBMSR fuel, 100\% $\mathrm{UCl}_{3}$, resulted in highly unstable simulations. In addition to numerical instability, the low viscosity of $\mathrm{UCl}_{3}$ is likely to result in turbulent flow for most relevant fuel configurations, so the laminar simulations of $\mathrm{NaCl}-\mathrm{UCl}_{3}-\mathrm{PuCl}_{3}$ produce a more conservative estimate of heat transfer. Detailed methodology and results of the mixed convection CFD study are described in Kasam et al. (2019).

In a subset of the simulated cases, referred to here as the "mixed heat transfer" (MHT) regime, convection and conduction effects are balanced in a stable flow, and a heat transfer correlation is obtained:

$$
N u_{M H T}=4.36 \exp (0.4954 \times \Omega)
$$

where $\Omega$ is a non-dimensional parameter relating the axial and radial heat fluxes, calculated in terms of the known boundary conditions,

$$
\Omega=-\frac{q^{\prime \prime \prime} d}{4 q_{w}^{\prime \prime}}
$$

The MHT regime is defined by $\Omega<4$. For higher values of $\Omega$, stronger convection gives rise to flow instability, so the BBMSR fuel design studies described in the following sections are limited to configurations with $\Omega<4$.

The MHT correlation can be used to calculate bulk temperature in section $\mathrm{A}, T_{A}$. In addition, the radial maximum-to-bulk temperature relationship was investigated in the CFD results. The relation is expressed as the ratio,

$$
\tau=\frac{T_{w}-T_{A}}{T_{w}-T_{\operatorname{Max}, A}}
$$

In the CFD simulations with $\Omega<4$, the average value of $\tau$ is 1.2. This value is implemented in the finite-difference model to estimate peak fuel temperatures within section A, so that the fuel can be designed within safe temperature limits. 


\section{Finite-difference model for concentric fuel}

A one-dimensional finite-difference model (FDM) is used to to calculate velocity and temperature distributions in the BBMSR concentric fuel tube sections. The newly developed MHT correlation is used to calculate heat transfer in section A, the inner section, while the Dittus-Boelter correlation is used for section B.

Fig. 4 illustrates the physical layout of the concentric tube with overall diameter $D$ and length $L$, and the nodalization scheme used in the FDM. With $N$ axial nodes in each section, there are $2 N$ nodes in total for which the energy and momentum balance are solved. A mesh sensitivity analysis was performed to show that $N=50$ produces results within $5 \%$ of the asymptotically converged results, for all values of $L$ considered in this study.
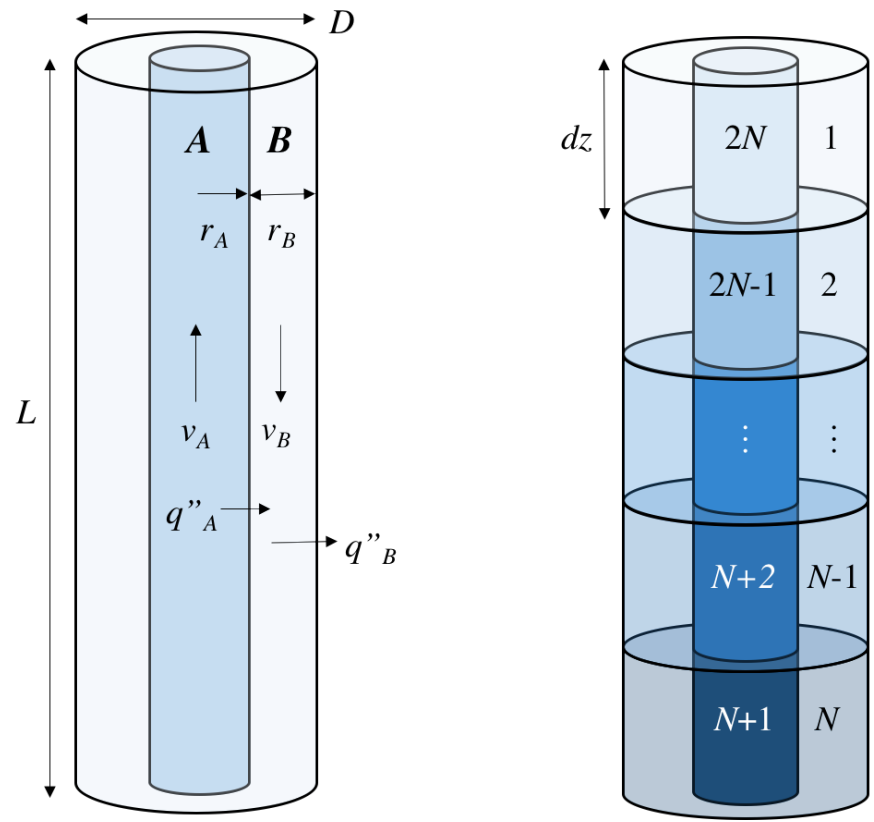

Figure 4: Concentric fuel tube layout and nodalization

The sizes of sections A and B are related by a parameter $\epsilon$, the ratio of section A cross-sectional area to total fuel element area, as

$$
\begin{gathered}
r_{A}=\frac{\sqrt{\epsilon D^{2}}}{2} \\
r_{B}=\frac{D}{2}-r_{A}-t_{w}
\end{gathered}
$$


where $t_{w}$ is the thickness of the inner wall between A and B (not depicted); $r_{A}$ is the radius of section $\mathrm{A}$; and $r_{B}$ is the annular thickness of section $\mathrm{B}$, i.e., the distance between inner wall and outer cladding. In addition to the overall fuel diameter, $\epsilon$ is a design parameter that can be tuned for optimal heat transfer from fuel to coolant. Mass continuity is satisfied by

$$
v_{B}=-v_{A} \cdot \frac{A_{A}}{A_{B}}
$$

$q_{A}^{\prime \prime}$ is the heat flux across the inner wall from section A to section B, and $q_{B}^{\prime \prime}$ is the heat flux across the outer cladding from section B.

\subsection{Energy balance}

Fig. 5 illustrates the balance of energy from IHG, axial convection, and radial conduction for general nodes in sections A and B. The IHG term in each node is the product of node volume and local heat generation rate $q_{z}^{\prime \prime \prime}$. It is assumed that $q_{z}^{\prime \prime \prime}$ varies axially with a chopped cosine power shape, representing the simplified neutron flux shape in a reactor with some axial neutron leakage, neglecting the effects of delayed neutron drift and axial reflectors at this stage:

$$
q_{z}^{\prime \prime \prime}(z)=q^{\prime \prime \prime} \cdot \cos \left(\frac{\pi z}{L_{e}}\right)
$$

where $q^{\prime \prime \prime}$ is the peak heat generation rate and $L_{e}$ is the height of the pin including the neutronic extrapolation length where the flux is zero.

The axial flow of thermal energy into and out of all nodes is given by $\dot{m} c_{P} T$. The FDM calculation is initialised with a random guess for $\dot{m}$, which is iteratively updated as the model converges on the velocity and temperature distribution solution.

The radial conduction energies $q_{A}$ and $q_{B}$ are calculated in terms of the differences between $T_{A}, T_{B}$, and the outer fuel temperature (i.e., inner cladding surface temperature) $T_{c i}$ as:

$$
\begin{gathered}
q_{A}=\frac{T_{A}-T_{B}}{R_{A}} \\
q_{B}=\frac{T_{B}-T_{c i}}{R_{B}}
\end{gathered}
$$

where $R_{A}$ and $R_{B}$ are the respective thermal resistances across each wall:

$$
R_{A}=\frac{1}{h_{A} r_{A} 2 \pi d z}+\frac{\ln \left(r_{w} / r_{A}\right)}{\kappa_{w} 2 \pi d z}+\frac{1}{h_{B} r_{w} 2 \pi d z}
$$




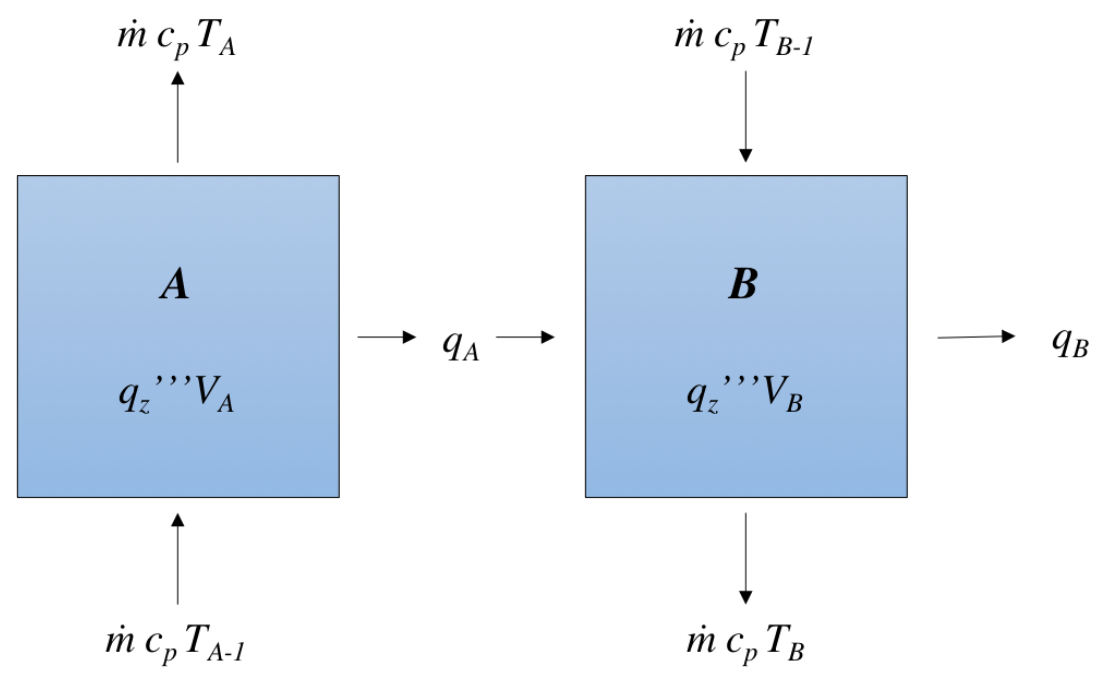

Figure 5: Energy balance on inner (A) and outer (B) fuel nodes

$$
R_{B}=\frac{1}{h_{B} D \pi d z}
$$

The outer radius of the inner wall is $r_{w}=r_{A}+t_{w}$. The heat transfer coefficient in each section is $h_{X}=N u_{X} \kappa_{f} / d_{X}$, where $X=A, B . N u_{A}$ is calculated using the MHT correlation (Eq. 2) and $N u_{B}$ is calculated using the Dittus-Boelter correlation (Eq. 1), as determined in Section 2.1. $\Omega$ is calculated using Eq. 3, where $q_{w}^{\prime \prime}=q_{A} /\left(2 \pi r_{A} d z\right)$ and $d=d_{A}$.

Energy terms are balanced by arranging a matrix of coefficients of $T_{i}$ and a matrix of known values (i.e., IHG and $T_{c i}$ terms), and solving for the bulk $T_{i}$ values by matrix division. Finally, the maximum radial temperatures in section A are estimated using Eq. 4 with $\tau=1.2$, where $T_{w}$ is the temperature of the inner wall at a given axial location. Assuming heat flux is constant across the inner wall from section A to section B, the axial profile of $T_{w}$ can be calculated:

$$
\frac{T_{A}-T_{w}}{1 /\left(h_{A} 2 \pi r_{A} d z\right)}=\frac{T_{A}-T_{B}}{R_{A}}
$$

\subsection{Momentum balance}

Momentum terms are balanced to solve for the bulk velocity in each fuel section. Since the fuel tube is a closed system with no externally imposed pressure gradient, the changes in gravitational and frictional pressure, $\Delta p_{g}$ and $\Delta p_{f}$ respectively, over both sections must sum to zero according to 
Bernoulli's principle. Using the axial temperature distribution from the energy balance calculation, the fuel density in each node $i$ is calculated using the $\mathrm{UCl}_{3}$ density correlation, $\rho_{i}=6.3747 \times 10^{3}-$ $1.5222 \times T_{i}[K]$ (Desyatnik et al., 1975). The net gravitational pressure drop over all nodes is found by summing terms in each section:

$$
\Delta p_{g}=\left(\sum_{i=1}^{N} \rho_{i} \cdot g \cdot d z\right)_{A}-\left(\sum_{i=1}^{N} \rho_{i} \cdot g \cdot d z\right)_{B}
$$

The velocities in A and B can then be solved by combining Eq. 7 with the equation for net frictional pressure drop:

$$
\Delta p_{f}=\left(f_{A} \cdot \frac{L}{d_{A}} \cdot \frac{\rho_{M} v_{A}^{2}}{2}+f_{B} \cdot \frac{L}{d_{B}} \cdot \frac{\rho_{M} v_{B}^{2}}{2}\right)
$$

where $\rho_{M}$ is the density at the mean temperature of all fuel nodes.

The friction factors $f_{X}$ are obtained using standard turbulent, transition, and laminar flow correlations. In turbulent flow with $\operatorname{Re}_{X}>30,000$, the McAdams relation for a smooth tube is applied in either section:

$$
f_{X}=0.184 R e_{X}^{-0.2}
$$

The Blasius relation gives the friction factor in transition flow, for $2300<R e_{X} \leq 30,000$ in either section:

$$
f_{X}=0.316 R e_{X}^{-0.25}
$$

For laminar flow with $R e_{X} \leq 2300$, molecular shear effects are significant over the flow crosssection, and the friction factor of an annular flow depends on the ratio of inner radius $r_{i}$ to outer radius $r_{o}$ (Todreas and Kazimi, 1990). Section A is a simple circular tube with $r_{i} / r_{o}=0$, while in section $\mathrm{B}, r_{i} / r_{o}=r_{A} / r_{B}$, which varies by fuel configuration. To simplify the model, section $\mathrm{B}$ is conservatively approximated as a parallel flat-plate channel with $r_{i} / r_{o}=1$, corresponding to the upper limit friction factor correlation. The respective laminar correlations are thus:

$$
\begin{aligned}
& f_{A}=64 / R e_{A} \\
& f_{B}=96 / \operatorname{Re}_{B}
\end{aligned}
$$

U-bend losses between sections, $\Delta p_{u}$, are neglected at this stage of analysis. Limited empirical data is available for loss coefficients in concentric geometries from annulus to pipe and vice versa, 
and a conservative estimate shows that the impact of these losses on the fuel thermal-hydraulic performance are likely to be small in the fuel geometries of interest. Pressure drop due to the $180^{\circ}$ annular bend is:

$$
\Delta p_{u}=\left(K_{b, A} \cdot \frac{\rho_{M} v_{A}^{2}}{2}+K_{b, B} \cdot \frac{\rho_{M} v_{B}^{2}}{2}\right)
$$

where $K_{b, A}$ and $K_{b, B}$ are the loss coefficients from pipe to annulus, and annulus to pipe, respectively. Very conservative values, $K_{b, A}=4.0$ and $K_{b, B}=10.0$, are estimated based on empirical data listed in Miller (1990). For the Base case assessed in Section 3.4, the peak temperature and temperature range both increase by about $2 \%$ compared to the values given in Table 3 , while $\Omega$ and $v_{A}$ remain nearly unchanged. Since the realistic $K_{b}$ values are likely to be considerably lower, $\Delta p_{u}$ is not included in the FDM.

Since the detailed design of the fuel element from a materials and manufacturing perspective is beyond the scope of this study, no mechanism for supporting the inner wall within the fuel element has been modelled at this stage. This is a non-conservative assumption, since any features connecting the inner to outer wall will increase the frictional pressure drop and impede the natural circulation flow.

\subsection{Iterative numerical schemes}

Since $N u_{B}$ is a function of $v_{B}$ and the velocities depend on the temperature distribution, the coupled temperature-velocity solution must be obtained iteratively. Using a Gauss-Seidel iteration scheme, an arbitrary guess for $\dot{m}$ initialises the energy balance routine of the FDM to find the temperature distribution, from which the momentum balance is calculated to update $\dot{m}$, and so on until the value of $\dot{m}$ converges. However, the Gauss-Seidel algorithm was found to be unstable for some input configurations, resulting in numerical oscillation between two solution modes.

Using the interval halving scheme instead, the energy balance is initialised with two arbitrary $\dot{m}$ guesses that generously bound the solution value of $\dot{m}$. The interval between $\dot{m}$ guesses is iteratively halved to eventually converge on the value of $\dot{m}$ that satisfies both energy and momentum balance. Interval halving is simple to implement in the FDM, converges quickly, and remains stable for all input configurations, so it is adopted as the preferred iterative scheme. 
An additional outer iteration loop is needed to converge on the value of $N u_{A}$ as a function of $\Omega$, which depends on the temperature distribution and $q_{A}$. This loop is found to be stable using the Gauss-Seidel scheme. It is initialised with the guess $\Omega=2.0$ (the median of the valid range), and the value of $\Omega$ is updated each time that a converged temperature-velocity solution is obtained in the inner iteration loop.

\subsection{FDM results and parametric study}

The FDM consisting of the iteratively coupled energy and pressure balances is embedded within a comprehensive fuel design search algorithm. The algorithm loops over many fuel configurations, taking some design parameters as inputs and searching for the optimal value of other parameters to satisfy several design objectives, including high power density, low core temperature rise, and low pumping power; these objectives are discussed further in Section 5.1. In each iteration, the algorithm calculates the bulk coolant and cladding temperatures based on geometry, power rating, and coolant velocity and properties. The inner cladding surface temperature is used as an input to the FDM energy balance, as outlined in Section 3.1. The design search algorithm is described thoroughly in Section 4.

In this section, the FDM is used as a standalone model to examine how axial temperature distributions in the concentric fuel are affected by varying diameter, length, and power density of the fuel, independently of the coolant channel parameters. The cladding inner surface temperature is defined simply as a linear gradient from $550^{\circ} \mathrm{C}$ at the bottom of the coolant channel to $700^{\circ} \mathrm{C}$ at the top. A base case is defined with $D=10 \mathrm{~mm}, L=2 \mathrm{~m}$, and $q^{\prime \prime \prime}=100 \mathrm{~W} / \mathrm{cm}^{3}$, similar to the design of the Moltex SSR fuel element $(10 \mathrm{~mm}$ diameter, $1.6 \mathrm{~m}$ active fuel length, and $150 \mathrm{~kW} / \mathrm{L}$

power density) (Scott, 2017). In case variant 1, $L$ is increased to $4 \mathrm{~m}$; variant 2 increases $D$ to 20 $\mathrm{mm}$; and variant 3 increases $q^{\prime \prime \prime}$ to $200 \mathrm{~W} / \mathrm{cm}^{3}$. The case inputs are listed in Table 1 .

For all four cases, $\epsilon=0.5$, and power density is distributed as a cosine power shape according to Eq. 8. The extrapolation length is assumed to be $L_{e}=1.5 \mathrm{~L}$ for all configurations, which corresponds to a relatively high axial leakage rate and low axial power peaking; the actual value of $L_{e} / L$ will depend on the realistic axial neutron flux shape in the BBMSR. Table 2 compiles the properties of $\mathrm{UCl}_{3}$ from literature. The inner wall is modelled as $0.3-\mathrm{mm}$ thick SiC, with thermal 
Table 1: Concentric fuel parameter study inputs

\begin{tabular}{lcccc}
\hline & Base case & Variant 1 & Variant 2 & Variant 3 \\
\hline$D(\mathrm{~mm})$ & 10 & 10 & 20 & 10 \\
$L(\mathrm{~m})$ & 2 & 4 & 2 & 2 \\
$q^{\prime \prime \prime}\left(\mathrm{W} / \mathrm{cm}^{3}\right)$ & 100 & 100 & 100 & 200 \\
\hline
\end{tabular}

conductivity $\kappa=30 \mathrm{~W} / \mathrm{mK}$ (Snead et al., 2007). Table 3 summarises the FDM results of the four cases by comparing the peak temperature, temperature range, average $\Omega$ value, and velocity of the fuel in section A. The axial temperature profile results for each of the four cases are also plotted in Fig. 6. The plots display the fixed input cladding inner surface temperature, $T_{c i}$; section B bulk temperature, $T_{B}$; inner wall temperature, $T_{w}$; and in section A both the bulk temperature $T_{A}$ and maximum radial temperature $T_{M a x}$.

Table 2: Thermophysical properties of $\mathrm{UCl}_{3}$

\begin{tabular}{ccc}
\hline Property & Equation/Value & Source \\
\hline Melting temperature, $T_{\text {melt }}(\mathrm{K})$ & 1073 & (Thoma, 1959) \\
Boiling temperature, $T_{\text {boil }}(\mathrm{K})$ & 2023 & (Ottewitte, 1982) \\
Density, $\rho\left(\mathrm{kg} \mathrm{m}^{-3}\right)$ & $6374.7-1.5222(T[\mathrm{~K}])$ & (Desyatnik et al., 1975) \\
Specific heat capacity, $c_{P}\left(\mathrm{~J}\left(\mathrm{~kg} \mathrm{~K}^{-1}\right)\right.$ & 435.6 & (Beneš and Konings, 2008) \\
Kinematic viscosity, $\nu\left(\mathrm{m}^{2} \mathrm{~s}^{-1}\right)$ & $10^{-1.2213+1100 /(T[\mathrm{~K}])} \times 10^{-6}$ & (Desyatnik et al., 1975) \\
Thermal conductivity, $\kappa\left(\mathrm{W}\left(\mathrm{mK}^{-1}\right)\right.$ & 0.5 & (Taube and Ligou, 1974) \\
Thermal expansion coeff., $\beta\left(\mathrm{K}^{-1}\right)$ & $3.43 \mathrm{E}-4$ & Calculated \\
Prandtl number, $\operatorname{Pr}$ & 1.70 & Calculated \\
\hline
\end{tabular}

In the base case (Fig. 6a), the temperature in section A increases almost linearly as the fuel moves upwards, approaching a peak around $0.8 \mathrm{~L}$ and remaining nearly flat to the top. The hot fuel moves into section B at the top and then loses heat through the cladding surface as it descends. The bulk temperature at the bottom is approximately $100^{\circ} \mathrm{C}$ hotter than the cladding surface tem- 
Table 3: Concentric fuel parameter study results

\begin{tabular}{lcccc}
\hline & Base case & $\begin{array}{c}\text { Variant } 1 \\
(L=4 \mathrm{~m})\end{array}$ & $\begin{array}{c}\text { Variant 2 } \\
(D=20 \mathrm{~mm})\end{array}$ & $\begin{array}{c}\text { Variant 3 } \\
\left(q^{\prime \prime \prime}=200 \mathrm{~W} / \mathrm{cm}^{3}\right)\end{array}$ \\
\hline Peak $T\left({ }^{\circ} \mathrm{C}\right)$ & 1136 & 1120 & 1155 & 1364 \\
$T$ range $\left({ }^{\circ} \mathrm{C}\right)$ & 478 & 487 & 387 & 666 \\
$\Omega$ & 2.5 & 1.9 & 6.6 & 2.7 \\
$v_{A}(\mathrm{~m} / \mathrm{s})$ & 0.08 & 0.12 & 0.17 & 0.14 \\
\hline
\end{tabular}

perature.

For variant 1 with $L=4 \mathrm{~m}$ (Fig. 6b), the temperature distribution is more skewed, with a larger difference between sections A and B in the top half compared to the base case. The value of $\Omega$ is smaller than the base case, but the peak temperature and range are similar, indicating that the overall fuel heat transfer performance is not affected significantly by height, given the same surface temperature range. In a realistic fuel system, the coolant will accumulate more heat as it flows up through a longer channel so $T_{c i}$ will have a larger range. In addition, a larger coolant pressure drop in a longer channel may reduce the allowable coolant mass flow rate.

For variant 2 with $D=20 \mathrm{~mm}$ (Fig. 6c), $\Omega=6.1$ and therefore $N u_{A}=90$ according to the MHT correlation (Eq. 2). This high $N u_{A}$ makes $T_{A}$ only slightly hotter than $T_{w}$ in Fig. 6c. The minimum temperature is significantly hotter than for the previous cases, but the peak temperature is similar. However, the MHT correlation is valid only for $\Omega \leq 4$, since the mixed convection flow is likely to be unstable at higher values of $\Omega$ (Kasam et al., 2019). Therefore, the calculated $N u_{A}$ of variant 2 is non-physical and the configuration would be excluded from the design search.

Variant 3 with $q^{\prime \prime \prime}=200 \mathrm{~W} / \mathrm{cm}^{3}$ (Fig. 6d) has a similar $\Omega$ value and temperature profile shape to the base case. The temperatures are effectively scaled up due to the higher power, with the peak temperature $300^{\circ} \mathrm{C}$ hotter, and the range larger by $225^{\circ} \mathrm{C}$.

Overall, the FDM parameter study shows that the value of $\Omega$ corresponds to the shape of the temperature profile. The difference between $T_{A}$ and $T_{B}$ shrinks as $N u_{A}$ improves with increasing $\Omega$. 


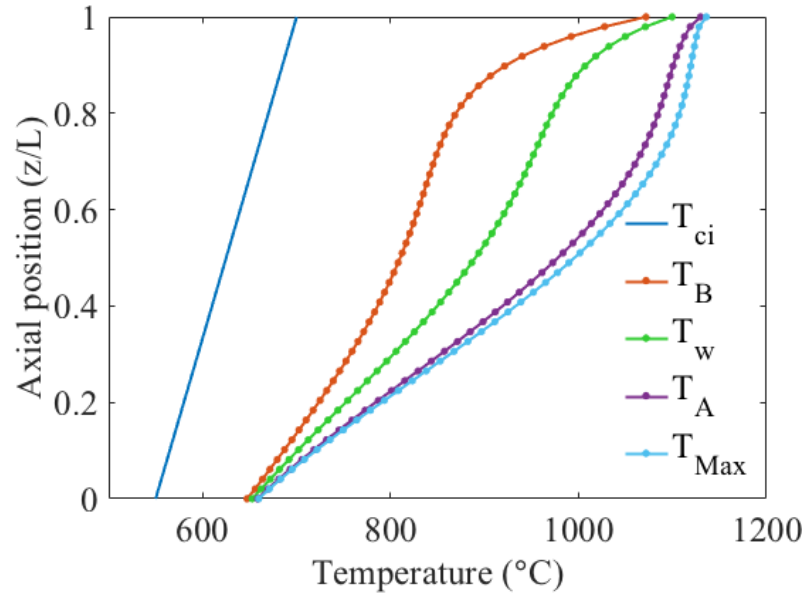

(a) Base case

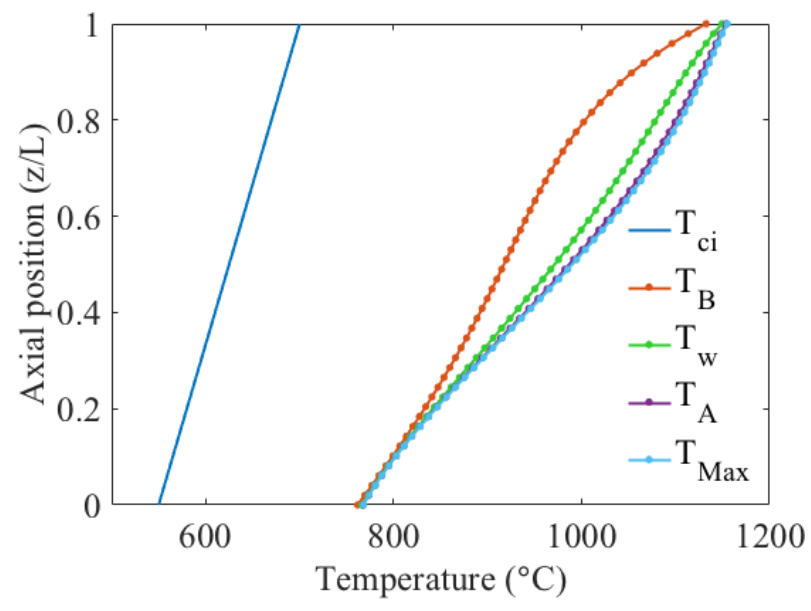

(c) Variant 2: diameter increase

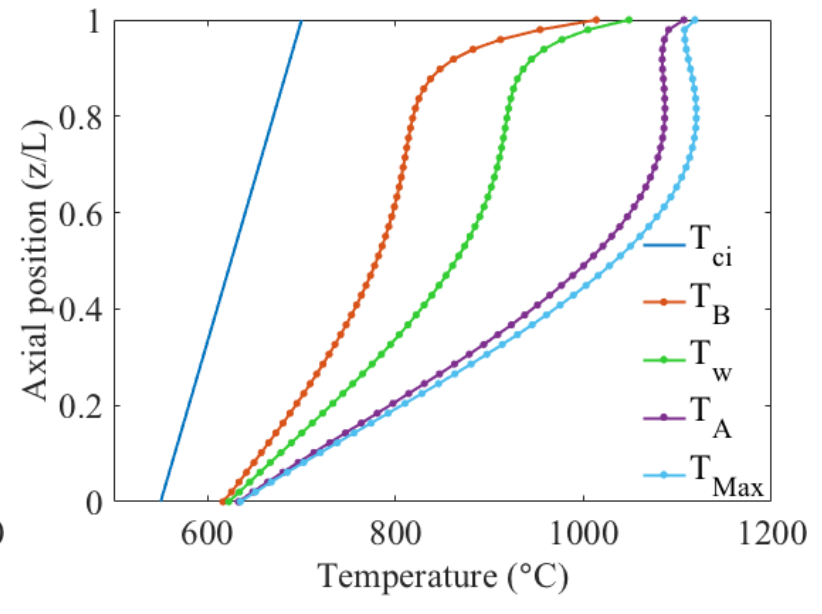

(b) Variant 1: length increase

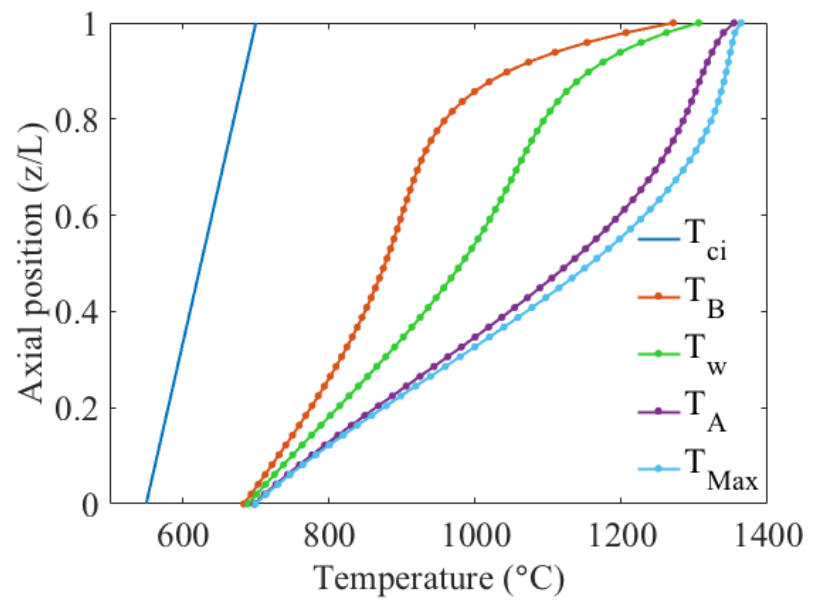

(d) Variant 3: power increase

Figure 6: FDM results of fuel parameter study with fixed cladding surface temperatures

\subsection{Concentric fuel flow area parametric study}

The parameter $\epsilon$, or the ratio of the section A cross-sectional area to the total fuel area, can be tuned for optimal heat transfer in each fuel configuration. Fig. 7 illustrates $\epsilon=0.5$ and $\epsilon=0.8$ for $D=10 \mathrm{~mm}$. The effect of $\epsilon$ on heat transfer performance is demonstrated using the FDM to evaluate the peak fuel temperature as $\epsilon$ is varied from 0.3 to 0.8. Fig. 8 shows the results for fuel configurations with $D$ ranging from $10 \mathrm{~mm}$ to $50 \mathrm{~mm}$, and fixed parameters $L=2 \mathrm{~m}$ and $q^{\prime \prime \prime}=100 \mathrm{~W} / \mathrm{cm}^{3}$. The peak fuel temperature increases sharply for larger values of $\epsilon$ with smaller tube diameters, since the frictional pressure drop increases as section B narrows, and convective 
heat transfer is reduced.

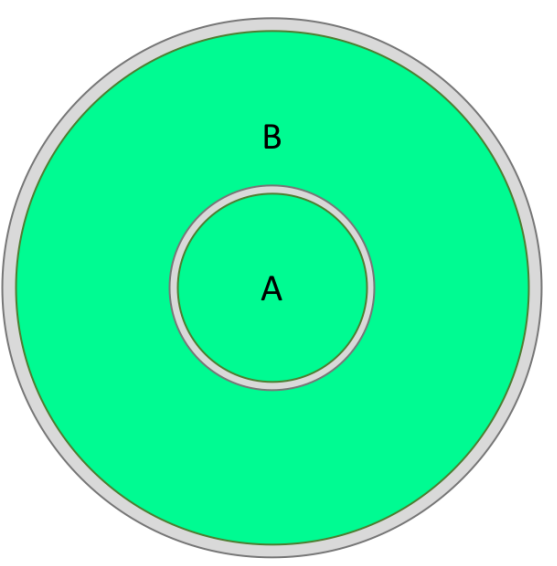

(a) $\epsilon=0.5$

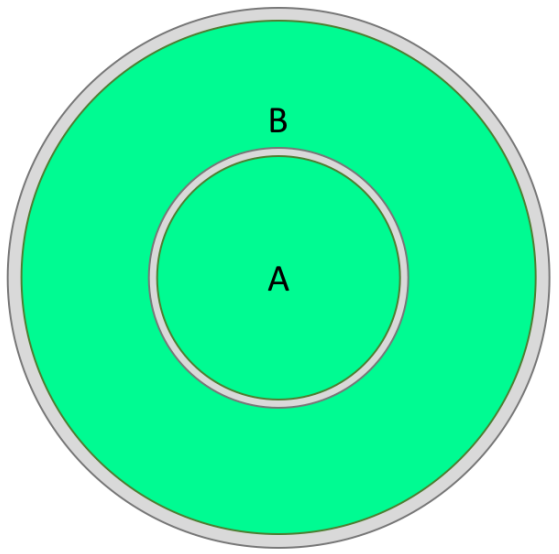

(b) $\epsilon=0.8$

Figure 7: Illustration of varying $\epsilon$ value for $D=10 \mathrm{~mm}$

While the fuel length and heat generation rate also slightly influence the optimal value of $\epsilon$, the trends remain similar to those shown in Fig. 8. Since all configurations appear to have an optimum roughly near $\epsilon=0.5$, this value is used for all comparison studies presented in this paper. In later design stages, $\epsilon$ can be optimised specifically for preferred configurations.

\section{Thermal-hydraulic design search algorithm}

An algorithm was developed to enable efficient thermal-hydraulic design of the BBMSR fuel. The algorithm is used to calculate performance impacts of various fuel geometries and to search for limiting operating parameters. It will be used in subsequent neutronic analysis to identify viable fuel designs.

\subsection{Inputs and constraints}

The fuel parameters $D, L$, and pitch-to-diameter ratio $(P / D)$ are entered as inputs to the design search algorithm. The thermal-hydraulic design of the BBMSR fuel is primarily constrained by pressure drop across the core and the temperature limits of fuel, cladding, and coolant materials. The wide range of potential design configurations and unusual behaviour of the convecting 


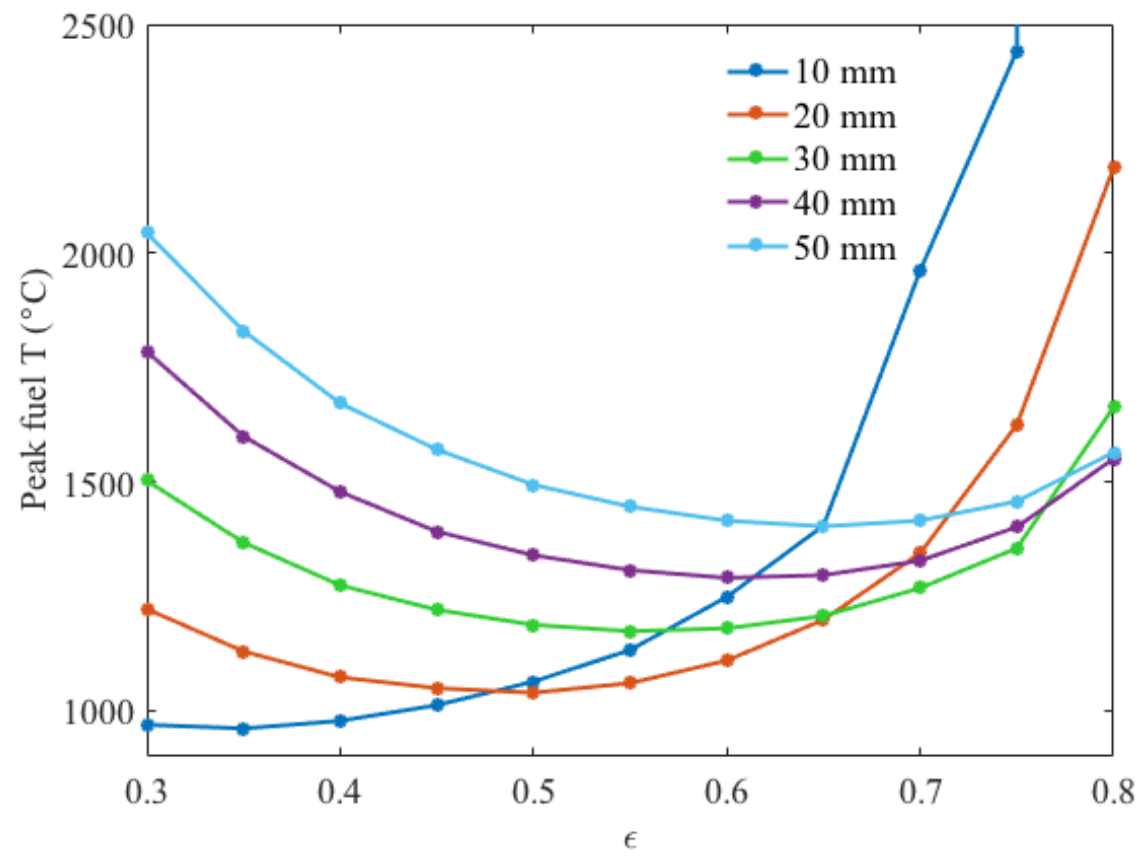

Figure 8: Optimal $\epsilon$ by fuel diameter

fuel leads to some non-obvious thermal-hydraulic interactions and trade-offs. Since the fuel and coolant salts have high melting temperatures, the system temperatures are limited at the lower as well as the upper end. The relatively high viscosities and low thermal conductivities of the molten salts introduce additional design challenges.

To manage this complexity, the search algorithm has been developed with only three fixed thermal-hydraulic constraints: maximum fuel temperature, core pressure drop, and core outlet temperature. These constraints are explicitly defined at the highest level of the search calculation, and they are satisfied by iterating to find the limiting values of power density and coolant mass flow rate, given the fuel geometry inputs. The allowable maximum fuel temperature is a safety constraint, while the maximum pressure drop is an economic and operational constraint.

The remaining performance parameters are treated as flexible constraints, since their target values may need to be adjusted based on the results of initial design iterations, or because of uncertainties in material properties. The flexible constraints are used as criteria applied to a set of results, to evaluate and narrow the design parameters for the next design iteration. This approach allows more flexibility and transparency in the design process, as opposed to explicitly limiting 
the values of many parameters. Calculated results for some configurations that fail to meet certain requirements or targets may still provide valuable information that guides the next design iteration.

\subsection{Algorithm description}

The coolant mass flow rate is calculated based on the geometry inputs and maximum pressure drop constraint,

$$
\Delta p_{\text {channel }}=\frac{f_{m} G_{m}^{2} L}{2 D_{e} \rho_{m}}
$$

The coolant flow is assumed to be turbulent for most realistic channel correlations, so the McAdams correlation (Eq. 16) is used to find $f_{m}$. A hexagonal lattice is adopted, since it allows larger fuel volume fractions without prohibitively high pressure drop, compared to a square lattice. The mass flow rate is thus derived:

$$
\dot{m}_{m}=\left[\frac{f_{m} G_{m}^{2}}{0.184}\left(\frac{\mu_{m}}{D_{e}}\right)^{-0.2}\right]^{1 / 1.8} A_{h e x}
$$

where $A_{\text {hex }}$ is the hexagonal coolant channel coolant flow area,

$$
A_{\text {hex }}=2 \sqrt{3} P^{2}-\frac{\pi}{4} D^{2}
$$

and $D_{e}$ is the equivalent hydraulic diameter,

$$
D_{e}=\frac{4 A_{h e x}}{\pi D}
$$

The algorithm then iteratively solves for the value of $q^{\prime \prime \prime}$ that results in the maximum allowable fuel temperature and defined core outlet temperature, as illustrated in Figure 9. The interval halving scheme described in Section 3.3 is used to ensure stable convergence. As the power is updated in each iteration, the axial coolant and cladding temperature profiles are calculated and used as inputs to the FDM, which returns the values of $\Omega, T_{w}, T_{B}$, and $T_{M a x}$. The key performance parameters and flexible constraints are calculated as outputs. The fuel heat generation rate $q^{\prime \prime \prime}$ is converted to channel power density, which takes into account the volume of all the fuel, cladding, and coolant in the channel. 


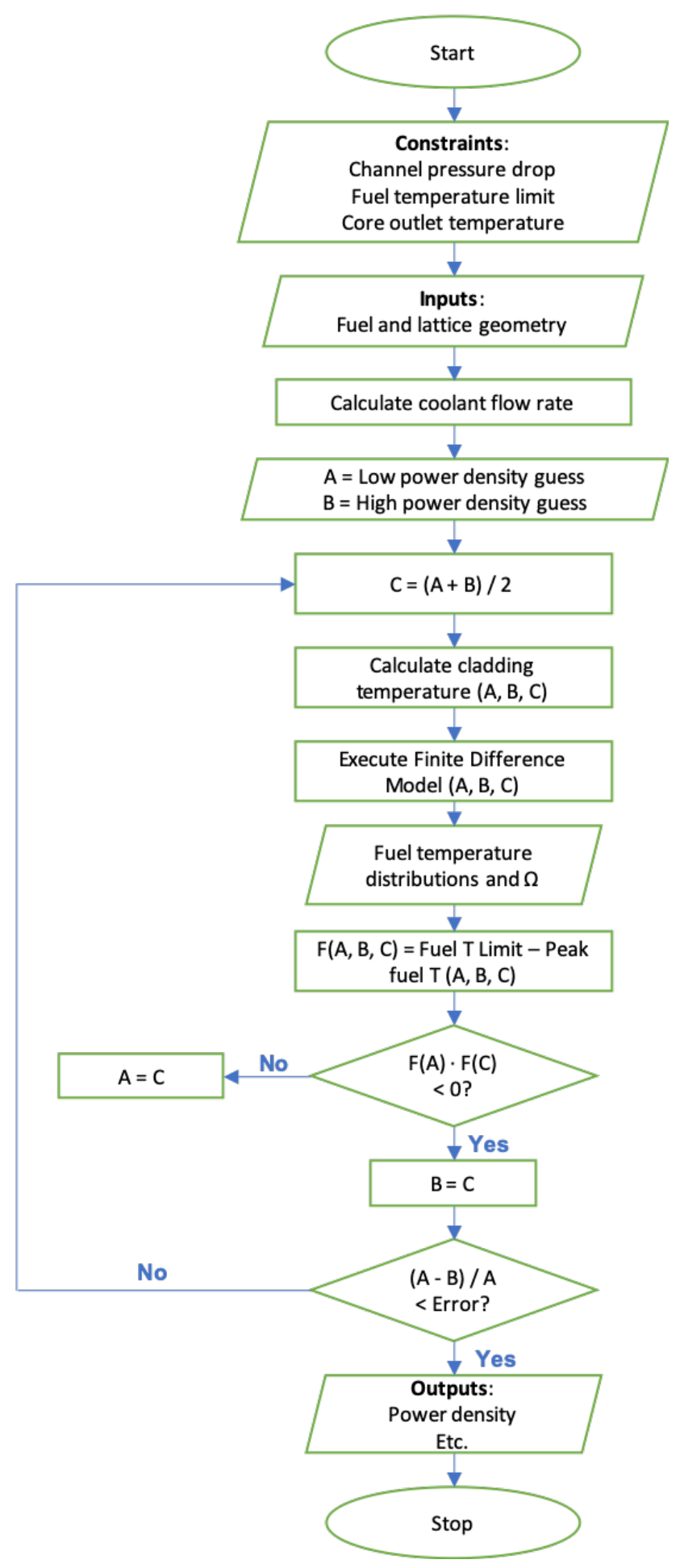

Figure 9: Flow chart of design search algorithm 


\section{Fuel Design Trade-Off Analysis}

A trade-off analysis is performed using the thermal-hydraulic design search algorithm to identify trends in the performance of the BBMSR concentric fuel design. The modelled geometry inputs are defined according to Table $4 . P / D$ is given for a hexagonal lattice. The modelled axial power shape is a chopped cosine with $L_{e}=1.5 \mathrm{~L}$.

Table 4: Geometry inputs for trade-off study

\begin{tabular}{lc}
\hline$D(\mathrm{~mm})$ & $10,12.5,15$ \\
$L(\mathrm{~m})$ & $2,3,4$ \\
$P / D$ & $1.10,1.12,1.14,1.16,1.18,1.20$ \\
$\epsilon$ & 0.5 \\
\hline
\end{tabular}

The fuel boiling point is assumed to be the most limiting temperature in the system. Since cladding temperature limit is reactor specific, further studies are required to establish a limit for the BBMSR cladding. The chloride coolant salt has a high boiling temperature that is unlikely to be approached in any practical fuel design configurations. Therefore, the maximum allowable fuel temperature is constrained to $1550^{\circ} \mathrm{C}$, which allows a $200^{\circ} \mathrm{C}$ margin from the estimated boiling temperature of $100 \% \mathrm{UCl}_{3}$ fuel.

The core pressure drop is physically limited by the system pumping power requirement and available pump technology. In this study the core pressure drop is fixed at $1 \mathrm{MPa}$, a roughly typical value for fast reactors (IAEA, 2006). The value is calculated simply as the frictional pressure drop in the coolant channel, using the McAdams correlation. Gravitational pressure drop within the coolant channel can be neglected if density changes are small, since it is balanced by the negative term from the return flow of coolant outside of the core. In a configuration with coolant pumped upward through the channel, neglecting gravitational pressure change is a conservative assumption since buoyancy aids the heated flow of coolant. Other sources of pressure loss due to expansion, contraction, and fuel spacers, which typically contribute around $15 \%$ of the total pressure drop in a fast reactor, are also excluded in this stage of analysis (Heidet, 2010). 
The coolant outlet temperature is fixed at $750^{\circ} \mathrm{C}$, and the algorithm solves for the inlet temperature in each fuel configuration. Most molten salt reactor designs have an outlet temperature between $700-850^{\circ} \mathrm{C}$ (Buongiorno et al., 2018). Outlet temperatures as high as $1000^{\circ} \mathrm{C}$ are targeted for future designs, based on the estimated capabilities of advanced structural materials.

The trade-off study is performed using properties of the ternary chloride eutectic $\mathrm{MgCl}_{2}-\mathrm{NaCl}-$ $\mathrm{KCl}(50-30-20 \%)$ for the coolant. This coolant was selected in a prior study on design of a molten salt-cooled fast reactor, which found it to have superior thermal-hydraulic and neutronic performance to other candidate coolant salts (Todreas et al., 2009). A discussion of its properties, including uncertainty and original data sources, can be found in Petroski et al. (2009).

The high fuel operating temperatures of the BBMSR demand a suitably resistant material for the outer cladding and inner wall. Candidate high-temperature materials including molybdenum and silicon carbide ( $\mathrm{SiC}$ ) will be evaluated neutronically in subsequent analysis. $\mathrm{SiC}$ is modelled in this trade-off study because it is assumed to have the most favourable combination of properties for the BBMSR. An outer cladding thickness of $0.5 \mathrm{~mm}$ is assumed, similar to other fast reactors, while the inner wall thickness is modelled as $0.3 \mathrm{~mm}$, since it does not need to support any load beyond its own weight. While SiC in particular has not yet been demonstrated with such thin cladding structures, the vented fuel design minimises stress on the structure because there is virtually no pressure difference across the cladding or inner wall, which should allow the use of thinner materials (George et al., 2015).

\subsection{Key performance parameters}

The key thermal-hydraulic performance parameters are core power density, core temperature rise, and pumping power. These parameters are related to the economics of building and operating the reactor. High core power density leads to a lower capital cost on a per MWe basis because the core size can be reduced for the same amount of power generated (Judd, 2014).

A small core temperature rise, $\Delta T_{\text {core }}$, is desirable because it reduces the required size and cost of heat exchangers; decreases axial thermal stresses on the cladding; and allows the core outlet temperature $T_{\text {out }}$ to be maximised within material temperature limits. High $T_{\text {out }}$ increases plant thermal efficiency, especially if the reactor is coupled to an advanced high-temperature power 
conversion system such as the air Brayton or supercritical- $\mathrm{CO}_{2}$ Brayton cycle. In addition, a reactor with high $T_{\text {out }}$ may be able to supply heat for industrial processes or store it for future use, increasing potential plant revenues. In the BBMSR, an axially homogeneous fuel composition also keeps axial power peaking low, which supports the goal of small $\Delta T_{\text {core }}$ and high $T_{\text {out }}$.

Small coolant pumping power is desirable to reduce the required pump size and cost, which directly impacts the reactor capital cost. In addition, the plant thermal efficiency is reduced by the power consumed for pumping, so this parameter should be minimised. Pumping power depends on the coolant mass flow rate and pressure drop, which are in turn related to the power density and $\Delta T_{\text {core }}$. For example, a larger power density requires more pumping power to maintain safe temperatures and small $\Delta T_{\text {core }}$, so these competing effects must be balanced.

Fig. 10 depicts the results from the design search calculation using the inputs given in Table 4 . Fig. 10a shows that the allowable channel power density decreases almost linearly as $P / D$ increases for a given fuel diameter and length. Although a looser pitch allows a higher fuel power rating $q^{\prime \prime \prime}$, compactness is sacrificed as a smaller proportion of the channel produces power, so the overall power density decreases. The allowable power density decreases significantly as the fuel diameter increases, like in solid fuel. As the length increases, the allowable power density decreases because the fixed core pressure drop is spread over a longer channel, so the coolant mass flow rate is reduced. The optimal configuration for maximising channel power density would have a small diameter and height, and a tight lattice. A typical LWR has a core power density of 100 $\mathrm{W} / \mathrm{cm}^{3}$, whereas an SFR can yield more than twice this figure. BBMSR fuel configurations with channel power density greater than $100 \mathrm{~W} / \mathrm{cm}^{3}$ are therefore considered economically competitive for the purposes of this study, and Fig. 10a shows that all of the modelled configurations achieve this target for $P / D<1.16$.

Fig. 10b shows the system's pumping penalty, or pumping power as a fraction of power generated in the channel. Since the pressure drop is fixed in this study, the coolant mass flow rate increases with increasing pitch and decreasing length, which in turn increases the required pumping power. Typical reactor pumping power for liquid coolants is between $1 \%$ and $10 \%$ of total reactor thermal power, and the pumping penalties seen in Fig. 10b fall within this range (Hejzlar et al., 2009). The pump is modelled as $100 \%$ efficient in this work, whereas a realistic pump 


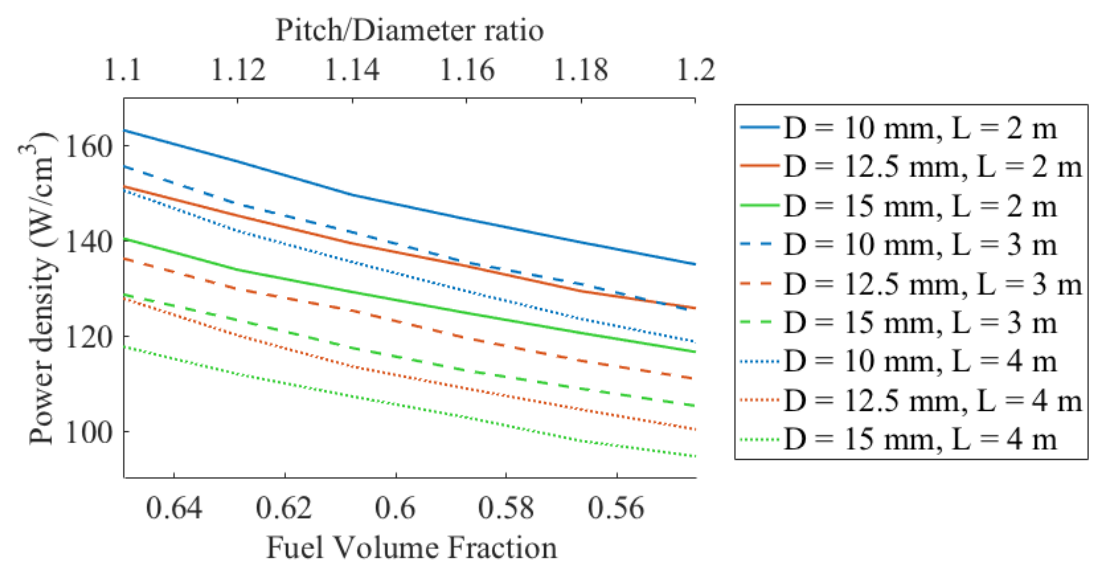

(a) Power density

Pitch/Diameter ratio

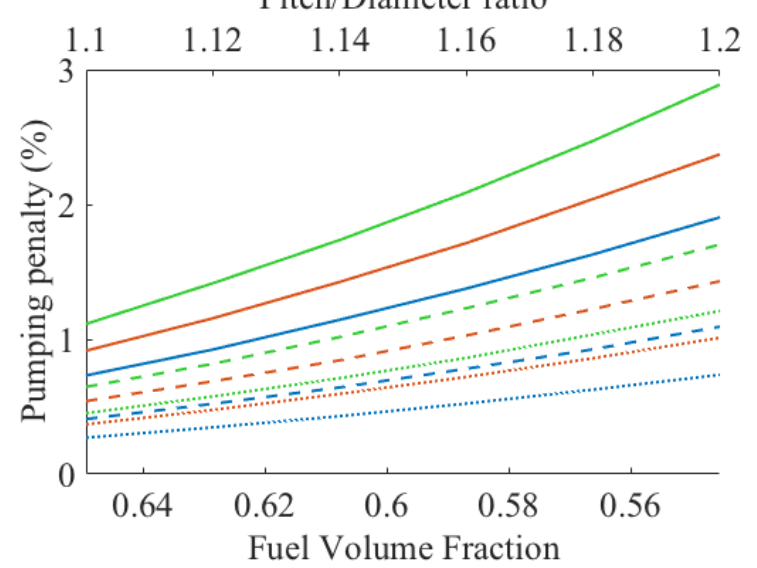

(b) Pumping penalty

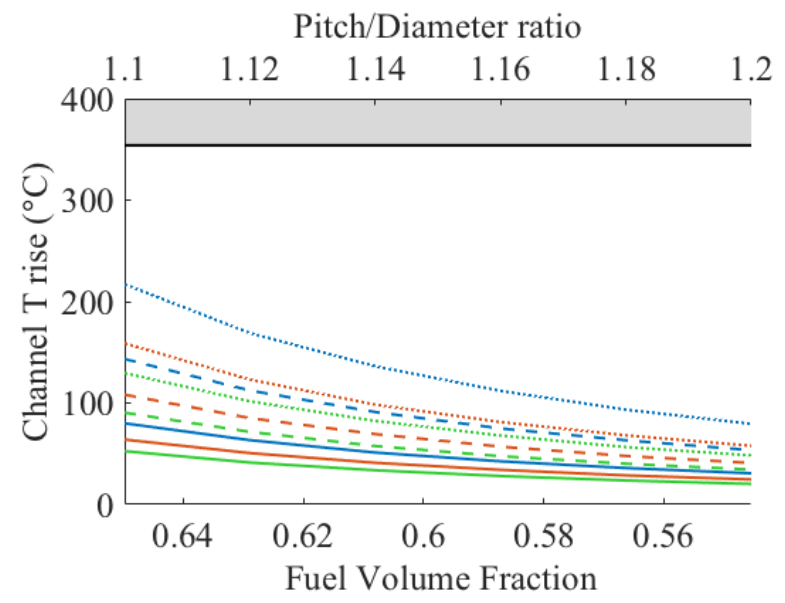

(c) $\Delta T_{\text {core }}$

Figure 10: Key performance parameters 
efficiency is 80-90\% (Todreas and Kazimi, 1990).

Fig. 10c shows that $\Delta T_{\text {core }}$ decreases as the channel pitch grows. With fixed pressure drop, the increasing coolant mass flow rate in a looser lattice reduces the temperature rise. For the BBMSR using the ternary chloride coolant, $\Delta T_{\text {core }}$ is constrained to no more than $354^{\circ} \mathrm{C}$, equal to the margin between the fixed $T_{\text {out }}\left(750^{\circ} \mathrm{C}\right)$ and freezing point of the coolant salt $\left(396^{\circ} \mathrm{C}\right)$. Most of the modelled BBMSR configurations have $\Delta T_{\text {core }}$ below $200^{\circ} \mathrm{C}$, even at $P / D=1.1$.

The three-dimensional plot in Fig. 11a depicts the interaction of channel power density, pumping penalty, and $\Delta T_{\text {core }}$, and each pair of parameters is also projected onto a two-dimensional plot. From Fig. $11 \mathrm{~b}, \Delta T_{\text {core }}$ decreases exponentially as pumping penalty increases regardless of the fuel geometry, so the optimal balance between these parameters lies somewhere in the middle of the range. From Fig. 11c, $\Delta T_{\text {core }}$ increases with power density for the given constraints, especially as the fuel lengthens. Fig. 11d shows that power density decreases as the pumping penalty grows, corresponding to increasing $P / D$. In summary, a high power density and low pumping power can be achieved simultaneously, but at the cost of a large $\Delta T_{\text {core }}$.

\subsection{Flexible constraints}

The minimum fuel temperature, maximum cladding temperature, maximum inner wall temperature, and $\Omega$ are evaluated as flexible constraints for the modelled fuel configurations. These outputs from the design search calculation are shown in Fig. 12.

The minimum fuel temperature is constrained by the melting point of $\mathrm{UCl}_{3}, 850^{\circ} \mathrm{C}$. In practice, the fuel will likely remain liquid slightly below the melting point due to turbulent mixing in the flow, so the minimum fuel temperature has not been imposed as a fixed constraint but is rather used as a design guide. However, Fig. 12a shows that most of the modelled configurations have a minimum fuel temperature well within the freezing range indicated by the shaded region. The minimum fuel temperature is smallest for the fuels with small $D$ and long $L$, since these also have a large $\Delta T_{\text {core }}$, as seen in Fig. 10c. This analysis demonstrates that avoiding fuel freezing is an additional motivation to minimise $\Delta T_{\text {core }}$.

The maximum outer cladding and inner wall temperatures are shown in Figs. 12b and 12c, respectively. Further material studies would be needed to quantify temperature limits for both 


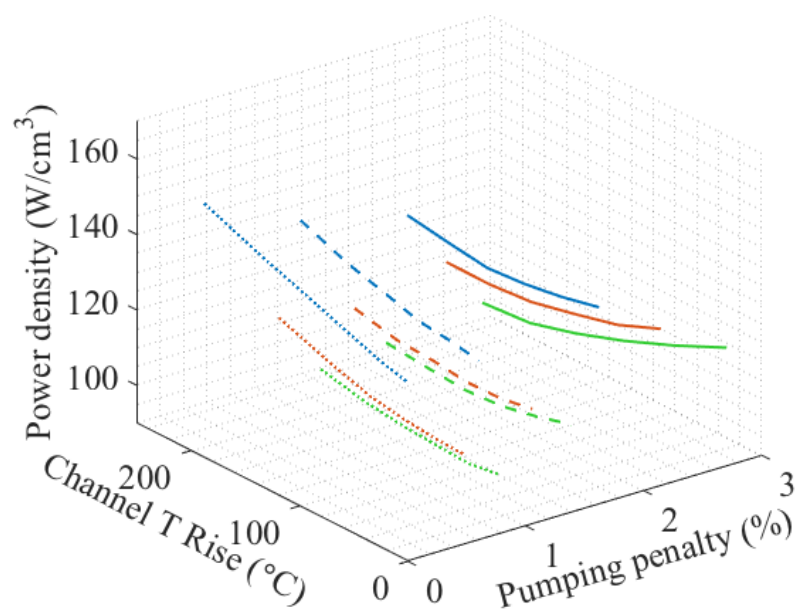

(a) 3D design space

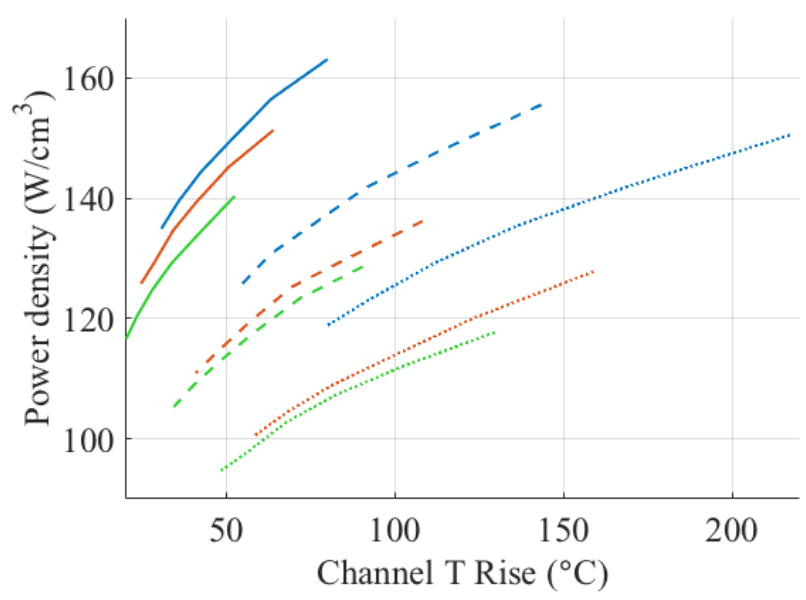

(c) $\Delta T_{\text {core }}$ versus channel power density

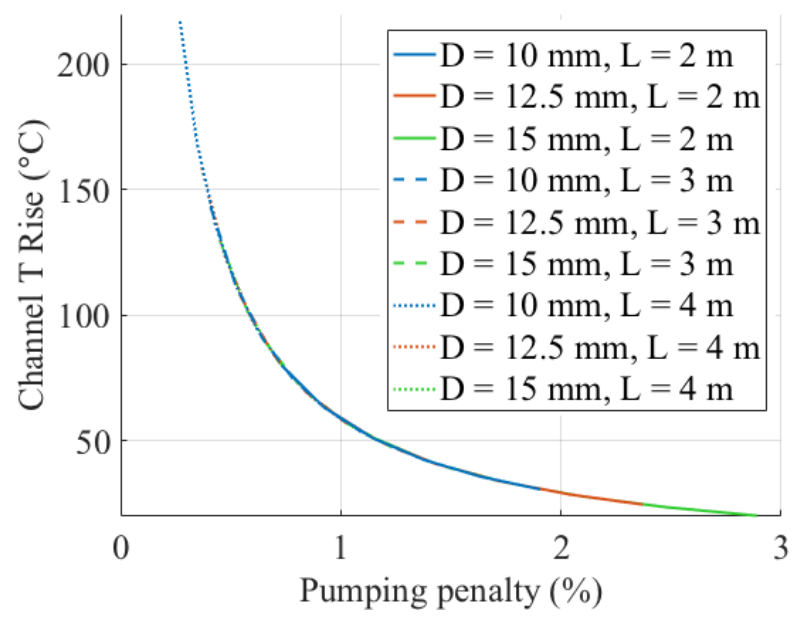

(b) Pumping penalty versus $\Delta T_{\text {core }}$

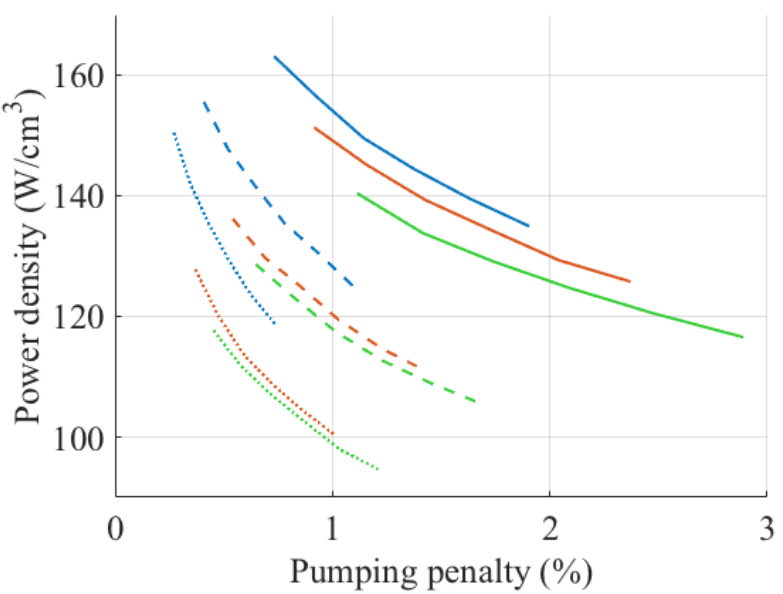

(d) Pumping penalty versus channel power density

Figure 11: Trade-offs of key performance parameters 


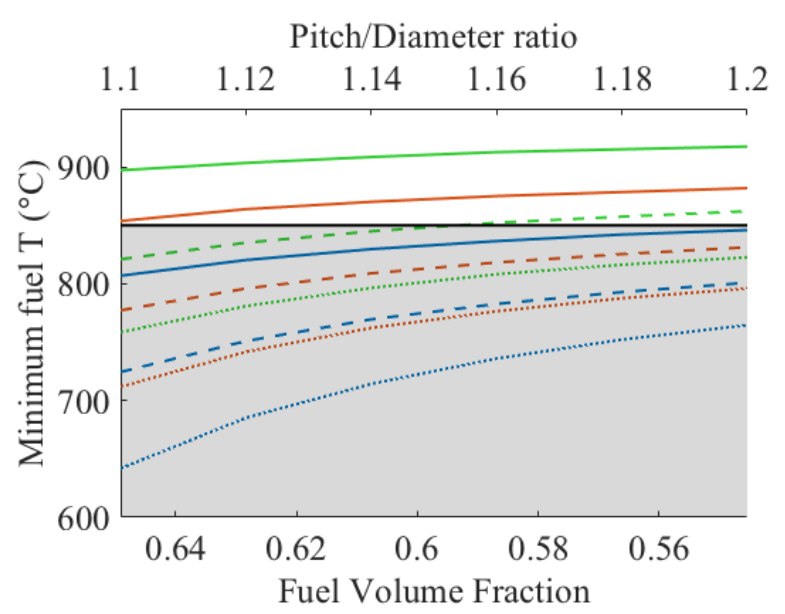

(a) Minimum fuel temperature

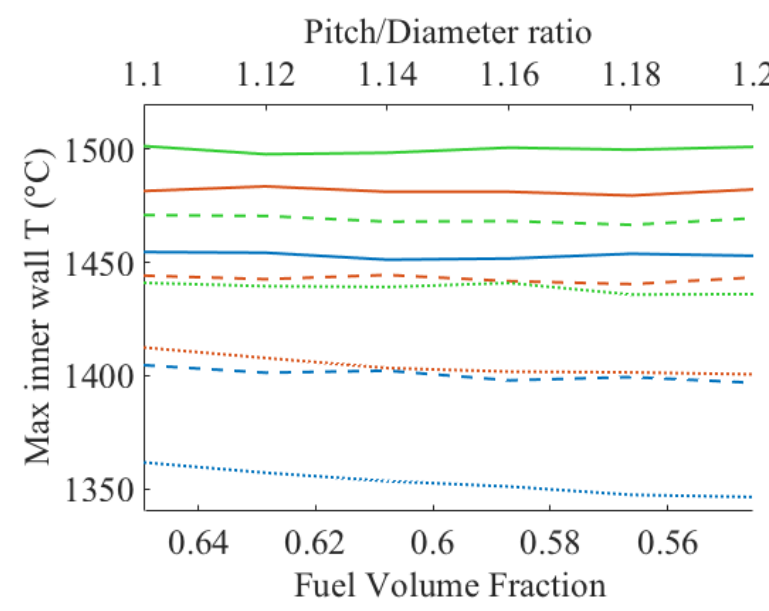

(c) Maximum inner wall temperature

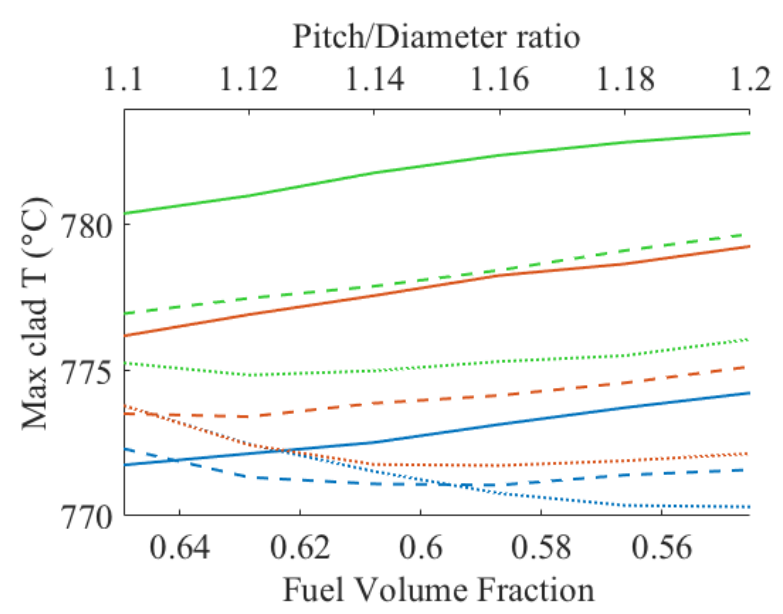

(b) Maximum cladding temperature

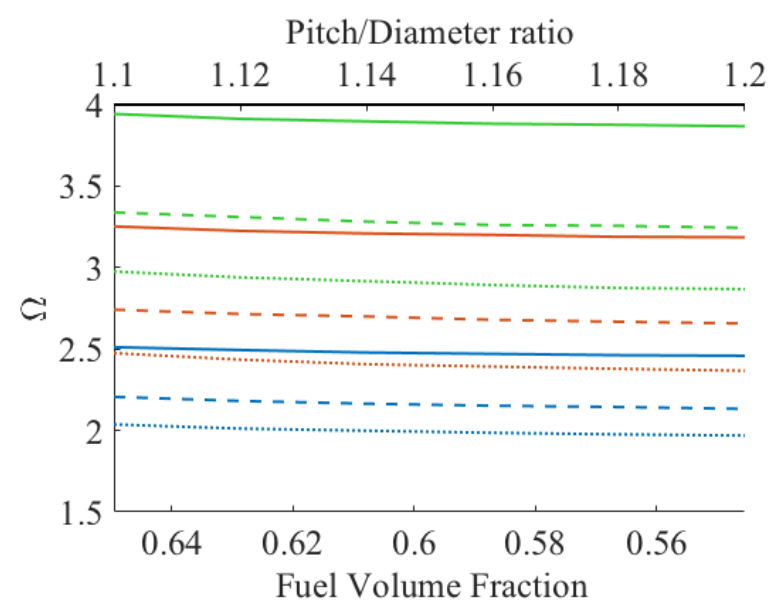

(d) $\Omega$

Figure 12: Flexible constraints (refer to legend of Fig. 11) 
outer cladding and inner wall. For the preferred material $\mathrm{SiC}$, the melting temperature is $2545^{\circ} \mathrm{C}$ and creep resistance in LWRs has been demonstrated up to $1600^{\circ} \mathrm{C}$ (Snead et al., 2007). The structural integrity of the outer cladding is important for safe reactor operation, and the maximum temperatures in Fig. 12b are well within the LWR creep temperature limit for SiC. However, the maximum inner wall temperatures shown in Fig. 12c are significantly higher, but since the inner wall is not structurally important, these high temperatures may be tolerable.

The value of $\Omega$ is calculated for all fuel configurations to check that they fall within the valid range of the MHT correlation $(\Omega \leq 4.0)$, where larger values of $\Omega$ are associated with unstable flow and were excluded from the correlation fitting (Kasam et al., 2019). The $\Omega$ limit is used to inform the design process, rather than explicitly constraining its value in the design search algorithm, and Fig. $12 \mathrm{~d}$ shows that the modelled fuel geometries do maintain $\Omega \leq 4.0$.

The trends observed for the cladding and inner wall temperatures and $\Omega$ can be attributed by similar phenomena. As discussed in Section 3.4, $\Omega$ increases with larger $D$ and shorter $L$, indicating improved heat transfer and smaller temperature differences radially across the fuel. As a result, the cladding and inner wall temperatures tend to be higher for these configurations, since the search algorithm identifies the power density that results in the maximum allowable fuel temperature. In addition, the maximum cladding temperature tends to increase with $P / D$, which may be attributed to more efficient cooling resulting in less radial temperature peaking of the fuel. $\Omega$ and the maximum inner wall temperature are not significantly affected by $P / D$.

\subsection{Coolant direction study}

Analysis of the key performance parameters in the trade-off study indicates that the advantages of high power density and low pumping penalty correspond to high $\Delta T_{\text {core }}$, which is undesirable for efficiency and cost considerations. A high $\Delta T_{\text {core }}$ also negatively affects the flexible constraints, since large temperature differences within the fuel element push the limits of both fuel boiling and freezing. A potential strategy to reduce $\Delta T_{\text {core }}$ without significantly impairing the other performance parameters is to reverse the direction of coolant flow, so that the coolant flows down the channel and increases in temperature from top to bottom. The hottest fuel always tends to occur near the top due to the internal natural convection effect, so reversing the coolant flow axially 
aligns the hotter fuel and colder coolant. The goal is to effectively "flatten" the channel average axial temperatures, so that the average moves closer to the maximum allowable temperature, and the power density can be increased.

The FDM is used to quantify the effect of coolant flow direction for a single representative fuel configuration. The base case defined in Section 3.4 is revisited as the upward coolant flow scenario, and the downward flow scenario is identical except that the cladding inner surface temperature profile $T_{c i}$ is reversed. Temperature distributions for the two scenarios are compared in Fig. 13, and key results are summarised in Table 5.

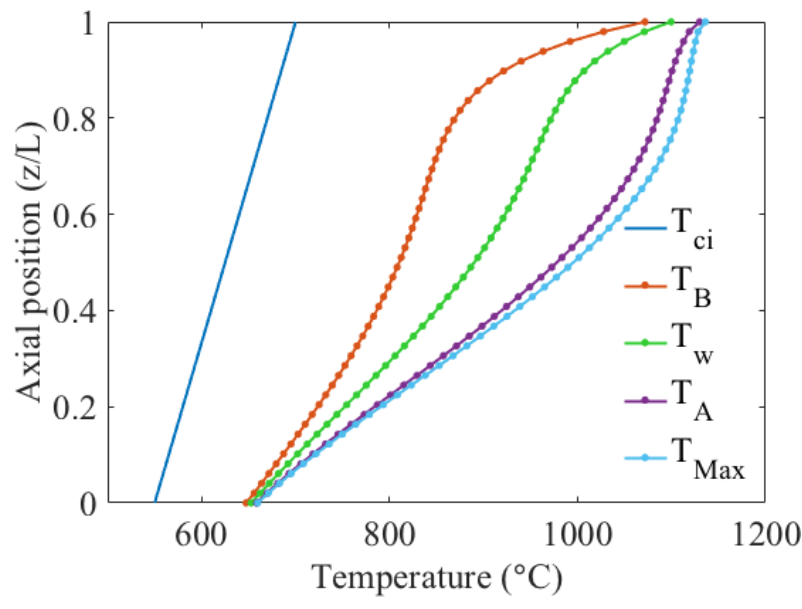

(a) Upward flowing coolant

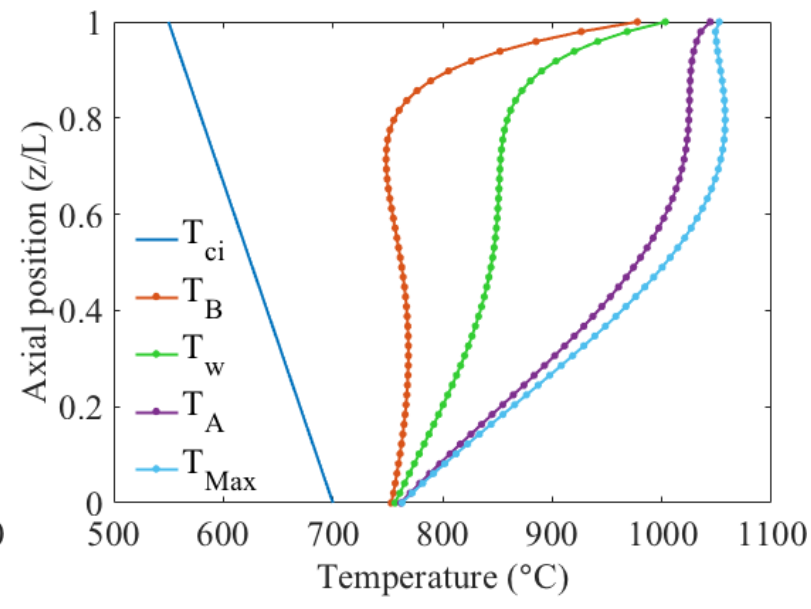

(b) Downward flowing coolant

Figure 13: Comparison of coolant flow direction scenarios

Table 5: Coolant flow direction comparison results

\begin{tabular}{lcc}
\hline & Upward flow & Downward flow \\
\hline Peak $T\left({ }^{\circ} \mathrm{C}\right)$ & 1136 & 1058 \\
$T$ range $\left({ }^{\circ} \mathrm{C}\right)$ & 478 & 296 \\
$\Omega$ & 2.5 & 2.0 \\
$v_{A}(\mathrm{~m} / \mathrm{s})$ & 0.12 & 0.12 \\
\hline
\end{tabular}

From Fig. 13a it is observed that the upward flow case is analogous to a counterflow heat 
exchanger, in which a fairly steady temperature differential is maintained between the hot and cold fluids (i.e., fuel and coolant) over the length of the channel. The downward flow case (Fig. 13b) is analogous to a parallel flow heat exchanger, in which the temperature differential is large at the inlet (top) and decreases over the length of the channel. In principle, parallel flow has lower heat cycle efficiency compared to counterflow, due to greater heat transfer irreversibility arising from the large temperature differential at the inlet. However, this condition is manifested as a lower peak fuel temperature and smaller fuel temperature range for a given BBMSR fuel configuration, which is advantageous to avoid freezing and boiling of the fuel salt.

Fig. 13 also shows that the maximum axial fuel temperature occurs near the top of the fuel element in both coolant direction cases, due to the buoyancy of the hotter fuel salt. This phenomenon is notably different from solid-fuelled systems, in which the fuel temperature peaks slightly above the centre when coolant is flowing upward, due to the increase in coolant temperature as it flows through the channel, but the axial fuel temperature profile would be exactly reversed if the coolant flowed downward. The advantages of downward flowing coolant are therefore particular to the BBMSR with convecting fuel salt.

The thermal-hydraulic design search algorithm is used to perform a parametric study for downward coolant flow, maintaining a fixed $T_{\text {out }}=750^{\circ} \mathrm{C}$ at the bottom of the channel. The other inputs and constraints used in the original trade-off study are kept the same, and the algorithm searches for the coolant inlet temperature at the top of the channel in each configuration. Since buoyancy opposes the direction of coolant flow in this configuration, the buoyancy contribution to gravitational pressure drop in the coolant is quantified as

$$
\Delta p_{\text {buoyant }}=\left(\rho_{\text {in }}-\rho_{\text {out }}\right) g L
$$

For the ternary chloride coolant with $\rho(T)$ given in Petroski et al. (2009), assuming $\Delta T_{\text {core }}=100^{\circ} \mathrm{C}$ and $L=4 \mathrm{~m}$, the buoyant pressure is calculated to be $\Delta p_{\text {buoyant }}=3.049 \mathrm{kPa}$, which is only $0.3 \%$ of the total core pressure drop $1 \mathrm{MPa}$. The gravitational pressure drop is therefore neglected for simplicity in modelling all downward flowing coolant configurations, and only the frictional pressure drop is considered.

The resulting key performance parameters from the downward flow parametric study are shown 
in Fig. 14. Fig. 14a shows that downward flowing coolant yields power densities approximately $10 \%$ higher than the upward flow results shown in Fig. 10a, without noticeably increasing either pumping penalty (Fig. 14b) or $\Delta T_{\text {core }}$ (Fig. 14c). Aligning the colder fuel with warmer coolant towards the bottom of the channel increases the minimum fuel temperatures (Fig. 14d), so that a larger subset of configurations are viable in terms of avoiding fuel freezing. Fig. 14e shows that $\Omega$ is also slightly reduced compared to Fig. 12 d, which will be advantageous when considering larger fuel $D$.

When less conservative heat transfer behaviour is assumed, the key performance parameters are similarly or even slightly more improved by the downward flow. For the configuration with $D=10 \mathrm{~mm}, L=2 \mathrm{~m}$, and $P / D=1.1$, effect of coolant direction is examined under two sets of assumptions. Using the MHT correlation in section A of the fuel tube, switching to downward coolant flow increases the allowable power density by $11 \mathrm{~W} / \mathrm{cm}^{3}$ up to $174 \mathrm{~W} / \mathrm{cm}^{3}$; minimum fuel temperature increases by $67^{\circ} \mathrm{C}$; and $\Omega$ decreases by 0.13 . Using the Dittus-Boelter correlation for forced turbulent convection in the fuel section A instead, the allowable power density increases by $26 \mathrm{~W} / \mathrm{cm}^{3}$ up to $200 \mathrm{~W} / \mathrm{cm}^{3}$; minimum fuel temperature increases by $82^{\circ} \mathrm{C}$; and $\Omega$ decreases by 0.21. This comparison demonstrates that downward flowing coolant improves the fuel's thermalhydraulic performance across a range of heat transfer conditions, and it is thus adopted as a key feature of the BBMSR concept.

\section{Discussion}

A thermal-hydraulic modelling approach is developed to support early design scoping studies for the dual-salt BBMSR. Numerous assumptions and modelling approximations have been employed to compensate for the scarcity of experimental data in this relatively unexplored domain. For instance, heat transfer correlations for IHG with buoyancy in a vertical tube were not found in the literature, so a CFD study was undertaken to develop one for the ascending flow in the central channel; while the forced-turbulent heat transfer correlation was applied in the descending flow in the annulus (Kasam et al., 2019).

In the CFD study, laminar flow and uniform IHG were assumed, but in reality the flow may be turbulent, and the power rate will vary axially due to neutron leakage. While efforts were made 


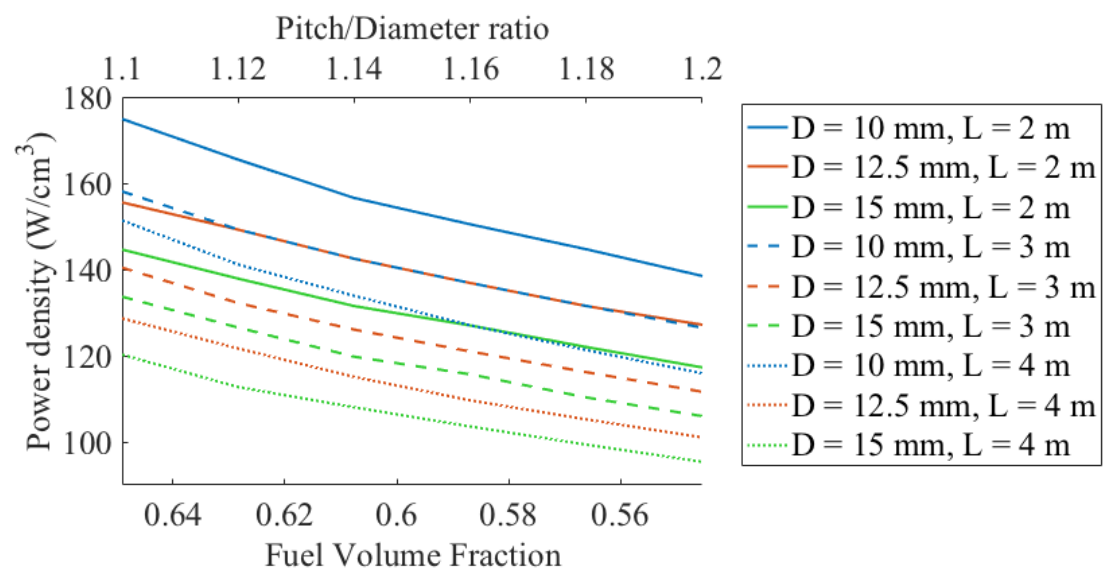

(a) Power density

Pitch/Diameter ratio

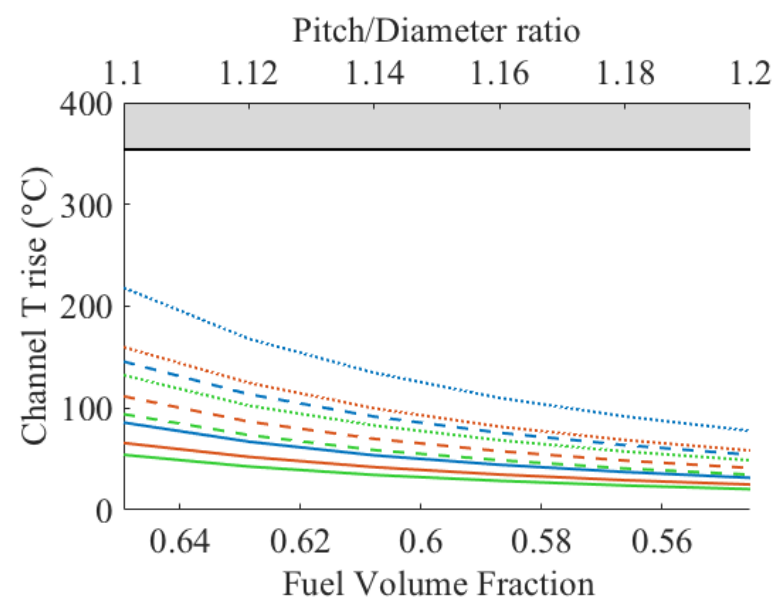

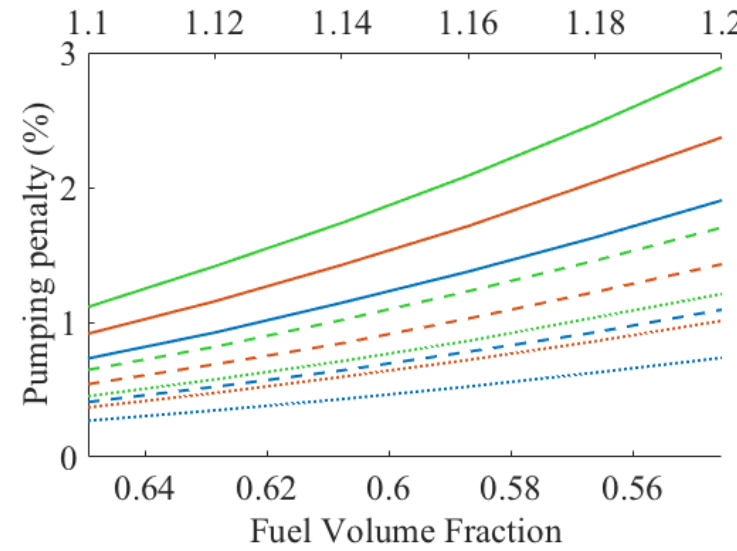

(b) Pumping penalty

Pitch/Diameter ratio

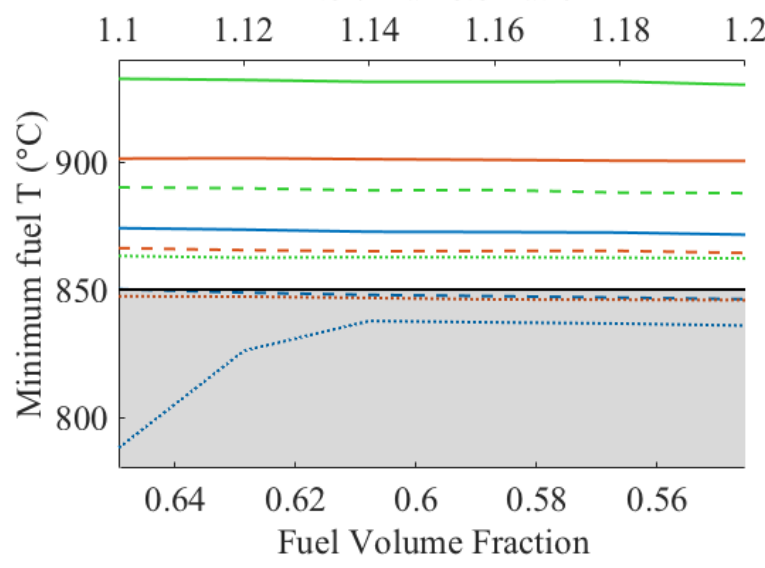

(d) Minimum fuel temperature (c) $\Delta T_{\text {core }}$

Pitch/Diameter ratio

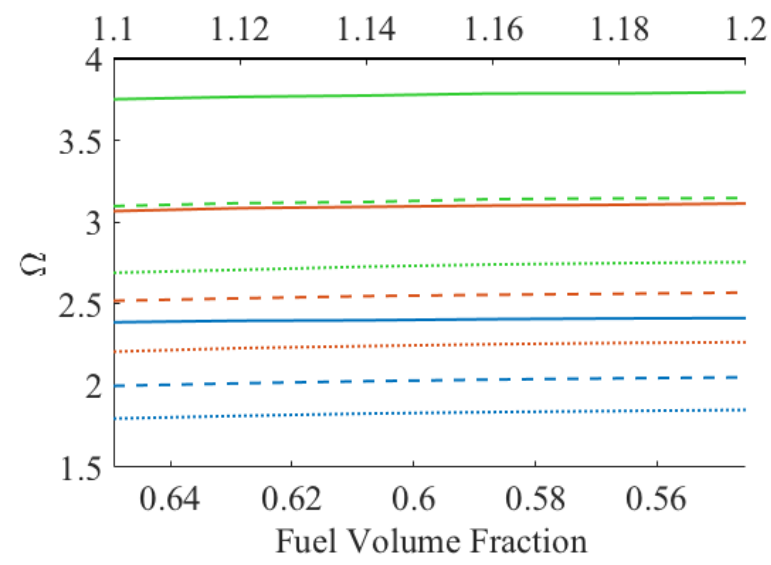

(e) $\Omega$

Figure 14: Downward flowing coolant results 
to verify the CFD models, experiments are ultimately needed to validate the simulations and to confirm the thermophysical properties of the candidate salts. In particular, high uncertainty is associated with the thermal conductivity of chloride salts (Petroski et al., 2009).

Additional approximations have been made to simplify analysis at this scoping stage, leaving model refinements and the inclusion of neutronic results for future design iterations. The structure to support the inner wall of the fuel element and the wire wrap around the pin have not been included in the model, but it should be noted that these will introduce additional pressure drop terms. In the FDM, power density is assumed to vary axially with a chopped cosine shape. The real power shape will depend on neutron leakage resulting from the axial configuration of the fuel assembly with reflectors, flow plenum, etc. In addition, the neutronic effect of different cladding materials must be evaluated and their realistic thickness requirements determined so that the cladding material can be modelled accurately in the FDM. Material compatibility between salt and cladding may also require experimental determination.

While linear stability analysis is commonly performed on naturally convecting systems, such analysis is beyond the scope of the present work at the design scoping stage. A stability analysis could be performed on a narrowed set of candidate fuel designs after neutronic scoping studies have been performed. However, it is noted that instabilities are very unlikely in the proposed convecting fuel configuration. The literature shows that flow reversal and oscillation can occur when in a symmetric convection loop with the hot leg horizontally below the cold leg; such phenomena disappear as the loop is rotated to a vertical configuration where the hot and cold legs are side-by-side (Wu and Sienicki, 2003; Mousavian et al., 2004; Misale, 2014). The BBMSR fuel tube features similar vertically parallel hot and cold legs, and the dividing wall between ascending and descending flows further prevents local oscillations. Given these characteristics, instability is unlikely occur in the fuel design, and a stability analysis can be performed at a later design stage.

\section{Summary \& Conclusions}

A finite-difference approach is developed to model the mixed convection flow of fuel in the inner and outer concentric sections of the BBMSR fuel concept. The MHT correlation, based on CFD analysis in a prior study, is incorporated into the FDM to model heat transfer in the 
inner channel section. Heat transfer and pressure drop correlations are used to balance energy and momentum terms for each node in the FDM. The model iteratively calculates the coupled temperature-velocity profiles until the mass flow rate converges. The FDM is used to perform a parametric study of the fuel concept, showing that the value of the non-dimensional parameter $\Omega$, which relates the axial and radial heat fluxes, corresponds to the temperature profile shapes in the concentric fuel. $N u$ of the inner channel section flow increases with $\Omega$ according to the MHT correlation, but a practical limit of $\Omega \leq 4$ is enforced for the fuel design studies.

The FDM is incorporated into an algorithm that iteratively searches for several thermal-hydraulic operational parameters within specified constraints, to enable efficient thermal-hydraulic design of the concentric BBMSR fuel. The algorithm identifies the maximum power density allowed within these limits and calculates the corresponding core temperature rise and pumping power requirement. Additionally, minimum fuel temperature, maximum temperature in the cladding and inner wall, and $\Omega$ are calculated. Even with small $P / D$, which is advantageous for neutron economy, the modelled fuel configurations can achieve power densities well above the targeted, economically competitive value of $100 \mathrm{~W} / \mathrm{cm}^{3}$. Reasonable values for the other thermal-hydraulic characteristics are obtained, except for excessively low minimum fuel temperatures that may lead to fuel freezing.

Thermal-hydraulic performance can be improved by reversing the direction of coolant flow, to downward flow. With the same inputs and constraints as for the upward flowing coolant, the allowable power densities are increased approximately 10\%, and the minimum fuel temperatures are increased so that most configurations are above the melting point of the fuel salt with a greater margin. Values of $\Omega$ are also decreased slightly, which helps to allow larger fuel diameters within the valid range of the MHT correlation.

The present work indicates that the BBMSR concentric fuel design with $100 \% \mathrm{UCl}_{3}$ fuel, ternary chloride coolant, and $\mathrm{SiC}$ cladding can satisfy thermal-hydraulic requirements and achieve competitive power densities. Although the high melting point of the fuel and resulting high operating temperatures of the system are challenging to balance with the other system constraints, the BBMSR's high outlet temperature could enable high plant thermal efficiency. In solid-fuelled reactors, even if advanced cladding materials are developed, metallic fuel has a relatively low melting 
temperature and low temperature of $\mathrm{Pu}-\mathrm{Fe}$ eutectic formation (Hejzlar et al., 2009). Use of molten salt fuel may confer a considerable advantage in this area. In the next stage of work, neutronic analysis will be performed to assess whether fuel configurations that can achieve economically competitive power density also exhibit the neutron economy required for B\&B operation.

\section{Acknowledgements}

The first author acknowledges financial support from The Winston Churchill Foundation of the United States, The Cambridge Commonwealth, European \& International Trust and a Churchill Pochobradsky Scholarship. We thank Zhiyao Xing of the University of Cambridge for advice regarding fuel design scoping.

\section{References}

Aicher, T., Martin, H., 1997. New correlations for mixed turbulent natural and forced convection heat transfer in vertical tubes. International Journal of Heat and Mass Transfer 40, 3617-3626. doi:10.1016/S0017-9310(97)00026-4.

Beneš, O., Konings, R.J.M., 2008. Thermodynamic evaluation of the $\mathrm{NaCl}-\mathrm{MgCl}_{2}-\mathrm{UCl}_{3}-\mathrm{PuCl}_{3}$ system. Journal of Nuclear Materials 375, 202-208. doi:10.1016/j.jnucmat.2008.01.007.

Buongiorno, J., Corradini, M., John, P., Petti, D., 2018. The Future of Nuclear Energy in a Carbon-Constrained World. MIT Energy Initiative , 275.

Desyatnik, V., Katyshev, S., Raspopin, S., Chervinskii, Y.F., 1975. Density, Surface Tension, and Viscosity of Uranium Trichloride-Sodium Chloride Melts. Atomnya Energiya 39, 70-72.

Feinberg, S.M., 1958. Discussion comment, in: International Conference on the Peaceful Uses for Atomic Energy, Geneva, Switzerland.

George, N.M., Terrani, K., Powers, J., Worrall, A., Maldonado, I., 2015. Neutronic analysis of candidate accident-tolerant cladding concepts in pressurized water reactors. Annals of Nuclear Energy 75, 703-712. doi:10.1016/j.anucene.2014.09.005.

Heidet, F., 2010. Maximum Fuel Utilization in Advanced Fast Reactors without Actinides Separation. PhD Thesis. University of California, Berkeley.

Hejzlar, P., Todreas, N.E., Shwageraus, E., Nikiforova, A., Petroski, R., Driscoll, M.J., $2009 . \quad$ Crosscomparison of fast reactor concepts with various coolants. Nuclear Engineering and Design 239, $2672-2691$. doi:10.1016/j.nucengdes.2009.07.007.

IAEA, 2006. Fast Reactor Database 2006 Update. IAEA-TECDOC-1531. International Atomic Energy Agency. Vienna, Austria. 
Jackson, J., Cotton, M., Axcell, B., 1989. Studies of mixed convection in vertical tubes. International Journal of Heat and Fluid Flow 10, 2-15. doi:10.1016/0142-727X(89)90049-0.

Jeong, Y.S., Seo, S.B., Bang, I.C., 2018. Natural convection heat transfer characteristics of molten salt with internal heat generation. International Journal of Thermal Sciences 129, 181-192. doi:10.1016/j.ijthermalsci.2018.01.036.

Judd, A.M., 2014. An Introduction to the Engineering of Fast Nuclear Reactors. Cambridge University Press, Cambridge.

Kasam, A., Lee, J.I., Shwageraus, E., 2019. Numerical study of heat transfer in ascending mixed convection with internal heat generation. Annals of Nuclear Energy 133, 138-144. doi:10.1016/j.anucene.2019.05.004.

Kasam, A., Shwageraus, E., 2017. Feasibility Studies of a Breed and Burn Molten Salt Reactor, in: Proceedings of ICAPP 2017, Fukui and Kyoto, Japan.

Martin, B., 1967. Free convection in a vertical cylinder with internal heat generation. Proceedings of the Royal Society of London 301, 327-341.

Miller, D.S., 1990. Turning flow - bends, in: Internal Flow Systems: Design and Performance Prediction. second ed.. Gulf Publishing Company, pp. 205-220.

Misale, M., 2014. Overview on single-phase natural circulation loops, in: Proc. of the Intl. Conf. on Advances In Mechanical And Automation Engineering, p. 13.

Mousavian, S.K., Misale, M., D’Auria, F., A. Salehi, M., 2004. Transient and stability analysis in single-phase natural circulation. Annals of Nuclear Energy 31, 1177-1198. doi:10.1016/j.anucene.2004.01.005.

Ottewitte, E.H., 1982. Configuration of a Molten Chloride Fast Reactor on a Thorium Fuel Cycle to Current Nuclear Fuel Cycle Concerns. PhD Thesis. University of California Los Angeles.

Petroski, R., Hejzlar, P., Todreas, N.E., 2009. Thermal hydraulic design of a liquid salt-cooled flexible conversion ratio fast reactor. Nuclear Engineering and Design 239, 2612-2625. doi:10.1016/j.nucengdes.2009.07.012.

Petroski, R.C., 2011. General Analysis of Breed-and-Burn Reactors and Limited- Separations Fuel Cycles. PhD Thesis. Massachusetts Institute of Technology.

Pini, A., Cammi, A., Cauzzi, M., Fanale, F., Luzzi, L., 2016. An Experimental Facility to Investigate the Natural Circulation Dynamics in Presence of Distributed Heat Sources. Energy Procedia 101, 10-17. doi:10.1016/j.egypro.2016.11.002.

Scott, I., 2017. Stable salt fast reactor, in: Molten Salt Reactors and Thorium Energy. Elsevier, pp. 571-580. doi:10.1016/B978-0-08-101126-3.00021-X.

Scott, I., Abram, T., Negri, O., 2015. Stable Salt Reactor Design Concept, in: Proceedings of the Thorium Energy Conference, Mumbai, India.

Sehgal, B.R., Dinh, T.N., Nourgaliev, R.R., 1996. Analysis of Natural Convection in Volumetrically-Heated Melt Pools. Technical Report. Swedish Nuclear Power Inspectorate and US Nuclear Regulatory Commission. Stockholm, Sweden. 
Snead, L.L., Nozawa, T., Katoh, Y., Byun, T.S., Kondo, S., Petti, D.A., 2007. Handbook of SiC properties for fuel performance modeling. Journal of Nuclear Materials 371, 329-377. doi:10.1016/j.jnucmat.2007.05.016.

Taube, M., Ligou, J., 1974. Molten plutonium chlorides fast breeder reactor cooled by molten uranium chloride. Annals of Nuclear Science and Engineering 1, 277-281. doi:10.1016/0302-2927(74)90045-2.

The OpenFOAM Foundation, 2017. OpenFOAM v5 User Guide.

Thoma, R.E., 1959. Phase Diagrams of Nuclear Reactor Materials. Technical Report. Oak Ridge National Laboratory. Oak Ridge, Tennessee.

Todreas, N.E., Hejzlar, P., Nikiforova, A., Petroski, R., Shwageraus, E., Fong, C.J., Driscoll, M.J., Elliott, M.A., Apostolakis, G., 2009. Flexible conversion ratio fast reactors: Overview. Nuclear Engineering and Design 239, 2582-2595. doi:10.1016/j.nucengdes.2009.07.014.

Todreas, N.E., Kazimi, M.S., 1990. Nuclear Systems Volume I: Thermal Hydraulic Fundamentals. Taylor \& Francis. Wu, Q., Sienicki, J.J., 2003. Stability analysis on single-phase natural circulation in Argonne lead loop facility. Nuclear Engineering and Design 224, 23-32. doi:10.1016/S0029-5493(03)00099-2.

Zhang, L., Luo, S., Zhang, Y., Tian, W., Su, G., Qiu, S., 2018. Large eddy simulation on turbulent heat transfer in reactor vessel lower head corium pools. Annals of Nuclear Energy 111, 293-302. doi:10.1016/j.anucene.2017.08.055.

\section{Nomenclature}

A Area

$D \quad$ Fuel diameter

$D_{e} \quad$ Equivalent hydraulic diameter

$L \quad$ Fuel length

$L_{e} \quad$ Extrapolation length

$N \quad$ Number of nodes

$\mathrm{Nu} \quad$ Nusselt number

$P / D$ Pitch-to-diameter ratio

$\operatorname{Pr} \quad$ Prandtl number 
$R \quad$ Thermal resistance

Re Reynolds number

$T \quad$ Temperature

V Node volume

$c_{P} \quad$ Specific heat capacity

d Hydraulic diameter of section

$d z \quad$ Node height

$f \quad$ Friction factor

$g \quad$ Gravitational acceleration

$h \quad$ Heat transfer coefficient

$\dot{m} \quad$ Mass flow rate

$\Delta p \quad$ Pressure drop

$q \quad$ Thermal energy

$q^{\prime \prime} \quad$ Heat flux

$q^{\prime \prime \prime} \quad$ Volumetric heat generation rate

$r \quad$ Hydraulic radius of section

$t \quad$ Thickness

$v \quad$ Velocity

$z \quad$ Distance from lower end of fuel

\section{Greek Symbols}


$\tau \quad$ Maximum-to-bulk temperature ratio

$\epsilon \quad$ Concentric fuel geometry ratio

$\kappa \quad$ Thermal conductivity

$\mu \quad$ Dynamic viscosity

$\Omega \quad$ MHT non-dimensional parameter

\section{Subscripts}

A Section A

B Section B

ci Cladding inner surface

$f \quad$ Frictional

$g \quad$ Gravitational

$i \quad$ Node index

M Mean

$m \quad$ Bulk coolant

out Outlet

$w \quad$ Inner wall

$X \quad$ Sections $A, B$

\section{Abbreviations}

B\&B Breed-and-burn

BBMSR Breed-and-burn molten salt reactor 
CFD Computational fluid dynamics

FDM Finite-difference model

FIMA Fission per initial heavy-metal atom

IHG Internal heat generation

MHT Mixed Heat Transfer

MSR Molten salt reactor

SSR Stable salt reactor 